\title{
The Use of Endoscopic Ultrasound-Guided Fine Needle Aspiration (EUS-FNA) in Cytopathology Diagnosis
}

\author{
Lee-Ching Zhu, Qinghua Feng and Verena S. Grieco \\ Additional information is available at the end of the chapter \\ http://dx.doi.org/10.5772/52549
}

\section{Introduction}

Since the introduction of endoscopic ultrasound (EUS) in the 1980s, EUS-guided fine needle aspiration (EUS-FNA) has become increasingly popular for the diagnosis and staging of gastrointestinal diseases, and peri-gastrointestinal lesions, especially in the areas of pancreatic or peri-pancreatic mass-like lesions. The application of FNA has dramatically expanded the clinical utility of EUS[1-10].

The aims of this chapter are to review:

1. The advantage of EUS-FNA in cytopathology diagnosis over other diagnostic modalities.

2. The impact of on-site cytological interpretation on the diagnostic yield of EUS-FNA.

3. The difference of application of ancillary techniques in cytological as compared to surgical specimens. What are the drawbacks but also the advantages of applying immunocytochemistry (ICC) in EUS-FNA obtained specimens.

4. Why EUS-FNA material can be an ideal source of material for molecular studies.

5. In summary, the full value of EUS-FNA can only be achieved with an integrated approach. We will illustrate this approach by one of our interesting EUS-FNA case studies.

\section{Aim 1: The advantage of EUS-FNA in cytopathology diagnosis over other diagnostic modalities}

In the absence of EUS-FNA, there are many alternatives for obtaining biopsy specimens of mass lesions in the chest and abdomen [11]. This is done most frequently by transcutaneous 
ultrasound (TUS), or CT-guided biopsy. Pathology specimens of obstructing lung masses and/or large paratracheal lymph nodes often are obtained at bronchoscopy with forceps or by transbronchial needle aspiration. Pathology specimens of pancreatic masses, especially those causing obstructive jaundice are still commonly obtained at the time of diagnostic or therapeutic ERCP (endoscopic retrograde cholangiopancreatography) with brushing, needle aspiration, or intraductal biopsy forceps. When lesions cannot be accessed by the above techniques, more invasive methods, such as mediastinoscopy or operative biopsy (laparoscopic or open) are used. The primary limitations of TUS and CT-guided aspiration include difficulty in accurately targeting small lesions and finding a safe-skin-to-lesion route, especially for deep-seated retroperitoneal, mediastinal or perirectal lesions. The diagnostic yield of pancreatic malignancies with ERCP biopsy is particularly problematic, with reported sensitivities ranging from $20 \%$ to $80 \%$, and most series having yields of a definitive malignant diagnosis of only around $50 \%$. The complication rate for ERCP cytologic brushing is reportedly as high as $11 \%$ for the biliary tree and $21 \%$ for pancreatic strictures [12-14].

Commercial radial echoendoscopes were introduced by the Olympus Corporation in 1987. Although EUS-FNA was performed successfully with radial echoendoscopes, it was not until 1991, when the linear-array echoendoscopes by Pentax Precision Instruments were introduced, that EUS-FNA has been extensively utilized for a variety of lesions. Fundamentally, EUS-FNA involves passing an 18- to 25-gauge aspiration needle through the biopsy port of an echoendoscope under real-time guidance into a EUS visualized mass lesion, lymph node, lesion within another organ, or fluid collection.

Although EUS is considered superior to MRI or CT with cross-sectional imaging for tumor detection smaller than 2 to $3 \mathrm{~cm}[15,16]$, it is the ability to target and place a needle into suspicious lesions at the closest proximity between the tip of the echoendoscope and the targeted lesion that has made EUS-FNA indispensable in the pre-operative diagnosis, especially in situations where neoadjuvant therapies or non-surgical management might be the clinical choice. Determining the role of EUS-FNA when alternative diagnostic modalities are available is difficult to assess in clinical trials; however, decision analysis models have been used to study the impact of EUS-FNA in lesions of many sites, including non-small-cell lung cancer with mediastinaladenopathy [17, 18], esophageal cancer and pancreatic cancer [19-21]. Commonly employed diagnostic modalities including CT-guided or US-guided FNA, ERCP with brushing, laparoscopic surgical biopsy and EUS-FNA have been analyzed for their costs, failure rate, testing characteristics and complication rate. In each of these analyses, EUS-FNA is the most cost-effective approach as the primary diagnostic modality and the preferred secondary alternative method after a failed initial diagnostic method as the least costly follow-up method.

The overall complication rate of EUS-FNA appears to be about 1-2\% [22, 23], comparable to that reported with CT or US-guided FNA or biopsy. However, another significant factor favoring EUS-FNA over transcutaneous biopsy is avoiding the possible risk of needle-tract seeding[24]. During EUS-FNA the aspiration needle travels from the gut lumen to the lesion, a pathway that usually does not involve significant crossing of peritoneal or pleural surfaces. In addition, endosonographers may have multiple options for the most accessible ap- 
proach to a lesion, such as through esophageal, gastric or duodenal path. In the case of pancreatic neoplasms, because of EUS-FNA imaging advantages, high diagnostic yields and concern over needle-tract seeding with transcutaneous aspiration, the $6^{\text {th }}$ edition of the handbook on cancer staging by the American Joint Committee on Cancer has recommended EUS-FNA as the preferred sampling technique in pancreatic masses if available[25].

Lastly, EUS-FNA has also opened the era of interventional endoscopic ultrasound (IEUS). In the same way as FNA, the close proximity between the needle tip and the targeted organ allows therapeutic procedures, such as injection therapies, to be performed safely and effectively. This includes EUS-guided celiac plexus neurolysis and block for pain relief, drainage of pancreatic pseudocysts and pelvic fluid collections, and implantation of fiducial markers and radioactive seeds into malignant tumors. Other emerging EUS-guided experimental techniques include antitumor injection, ablation of tumors, and vascular access. IEUS is a very promising technique with many potential applications [26-28].

On a different note, performance quality in endoscopy is becoming an important issue for patient care. Currently there is no universally accepted method for performance quality indicators in EUS, mostly because cancer staging accuracy cannot be verified without surgical resection. In addition, FNA yields of many sites (such as mediastinal lymph nodes) vary greatly based on pretest probabilities. Because most pancreatic masses that undergo EUSFNA have a very high pretest probability of being malignant and most endosonographers agree that pancreatic neoplasms are among the most difficult lesions on which to perform EUS-FNA, the diagnostic yield of EUS-FNA of solid pancreatic masses has become a benchmark for EUS-FNA quality. Much of the data for performance quality has come from series on pancreatic EUS-FNA, which is also the approach of most of our studies discussed in this chapter. In a multicenter retrospective study of 1075 patients who underwent EUS-guided FNA of solid pancreatic masses, the overall diagnostic rate of malignancy was $71 \%$, the median rate per center was $78 \%$ and the median rate per endoscopist was $75 \%$ [29], remarkably higher than any other aforementioned diagnostic modalities.

The ideal benchmark for pancreatic EUS-FNA performance, however, would be the actual sensitivity and specificity of diagnosing malignancy and require the criterion standard of either surgical pathology or long-term follow-up, which is the focus of our studies in the next section.

\section{Aim 2: Efficacy and utility of immediate cytologic interpretation on the diagnostic yield of EUS-FNA of solid and cystic pancreatic and peri- pancreatic lesions}

Intra-procedural on-site immediate interpretation by a cytopathologist is not performed in some clinical settings. Having a cytopathologist on site is time-consuming and diverts the pathologist from other duties, and the cytopathologist time is not compensated at the same rate as routine surgical pathology $[30,31]$. In the setting of service time pressure, there is a 
need for evidence based decisions regarding how to allocate pathologists. The clinical impact of immediate interpretation provided by cytopathologists during the EUS-FNA procedure and the statistical significance of this cytologic service has been welldocumented[32-43], although with variable conclusions. Many of the previous studies have included a wide range of disease entities sampled by EUS-FNA procedure. In addition, by including cystic lesions, previous analysis has been complicated by the high likelihood of acellular or pauci-cellular specimens obtained from the cystic lesions, which could be interpreted as inadequate on cytology. Thus, the clarity of outcome measurements from previous studies has been hindered by the complexity of the diseases included, and by inclusion of cystic lesions with an unduly high "inadequacy" rate. In addition, many previous studies have used clinical survival years as a surrogate for final assessment of diagnostic accuracy. Our goal in the hereby presented study is to use EUS-FNA of solid pancreatic masses as the benchmark procedure to compare diagnostic yield and accuracy in a strictly defined clinical setting of EUS-FNA performed in the presence or absence of on-site immediate cytologic interpretation. Histologic examination is used as the gold standard for comparison.

To avoid the confounding sampling issues of cystic lesions, this study was focused on the diagnostic yield of EUS-FNA in non-cystic pancreatic mass-like lesions. A computer inventory search located 215 cases during the years 1999-2007 at University of Washington Medical Center and Harborview Medical Center, both in Seattle, WA, USA. These included 100 cases where immediate cytologic interpretation was available and 115 cases without immediate interpretation. Surgical pathology and clinical follow-up information were evaluated whenever possible. Comparison between the cytologic diagnoses with or without on-site immediate cytologic interpretation was facilitated by well-documented cytology reports. "Positive" specimens were defined as suspicious or malignant cytology. "Inadequate" specimens were defined as "rare atypical cells, non-diagnostic"; "essentially acellular specimen", or "gastrointestinal tract carry-over material". "Negative" specimens were defined as "adequate cellularity with benign or reactive features".

As shown in Table 1, the rate of inadequate specimens was significantly lower for cases with immediate cytologic interpretation ( $1 \%$ versus $21 \%$; $p<0$. 0001). Although not statistically significant, there was a trend toward the need for fewer repeat procedures with the availability of immediate evaluation (rate $5 \%$ versus $10 \%$; $<<0.3$ ).

\begin{tabular}{lclll}
\hline & $\begin{array}{l}\mathbf{N}=\text { Positive } \\
\text { On Cytology }\end{array}$ & $\begin{array}{l}\mathbf{N}=\text { Negative } \\
\text { On Cytology }\end{array}$ & $\begin{array}{l}\text { Inadequate Case } \\
\mathbf{N}(\%)\end{array}$ & $\begin{array}{l}\text { Repeat EUS-FNA } \\
\text { Procedure N (\%) }\end{array}$ \\
\hline $\begin{array}{l}\text { Immediate Interpretation } \\
(\mathrm{N}=100)\end{array}$ & 39 & $1(1 \%)$ & $5(5 \%)$ \\
\hline $\begin{array}{l}\text { No immediate Interpretation 58 } \\
(\mathrm{N}=115)\end{array}$ & 33 & $24(21 \%)$ & $11(10 \%)$ \\
\hline PValue & & $<0.0001$ & $<0.3$ \\
\hline
\end{tabular}

Table 1. EUS-FNA of non-cystic pancreatic mass-like lesions with or without immediate interpretation for all cases $(\mathrm{N}=215)$ 
Of the 215 cases, surgical pathology follow-up was available for 55 cases. As would be expected, the majority of pancreatic mass lesions with surgical pathology comprised chronic pancreatitis $(n=14)$, pancreatic ductal adenocarcinoma $(n=29)$, and pancreatic endocrine neoplasms (n=7) (Table 2).

\begin{tabular}{ll}
\hline Case Type & Case Number (N) \\
\hline Chronic pancreatitis & 14 \\
\hline
\end{tabular}

Table 2. Cases with histologic diagnoses (total $\mathrm{N}=55$ )

With histologic follow-up, we identified one false positive case, both at immediate interpretation and at final cytologic review, for which no neoplasm was identified at the open surgery or at repeat EUS-FNA procedure; this may have been a reactive mass that resolved after resolution of inflammation (with 12 months follow up). Cases with negative cytology results usually do not progress to surgical intervention, and surgical resection is also not performed in cases with unresectable malignancy. Due to the expected small number of cytologically negative cases with histologic follow-up, the single false positive case would have weighed un-proportionally in the calculation of specificity and positive predictive value. False negative cases represented well-differentiated pancreatic adenocarcinomas and cases of unrepresentative sampling, including one case of fibromatosis of pancreas. The number of cases with diagnostic discrepancy between cytologic and histologic diagnoses, and the corresponding statistical values, are summarized in Table 3 and Table 4 . When comparing cases with on-site cytopathology immediate interpretation to those without, there was a trend toward greater sensitivity $(83 \%$ versus $65 \%, \mathrm{p}=0.19)$ with similar specificity $(86 \%$ versus $100 \%, \mathrm{p}=0.29)$. There was also a trend toward lower cytologic-histologic discordance rate in cases with availability of immediate interpretation by cytopathologists $(16 \%$ versus $27 \%, \mathrm{p}=0.34)$. Positive predictive value was comparable for cases where cytopathologists were present on-site compared with cases where no cytopathologists were present ( $94 \%$ versus $100 \%, \mathrm{p}=0.32)$, but the availability of immediate interpretation resulted in a higher negative predictive value (67\% versus $47 \%, \mathrm{p}=0.34)$. 


\begin{tabular}{llllll}
\hline N=Positive & $\begin{array}{l}\text { N= Positive } \\
\text { cytology, } \\
\text { neoplastic } \\
\text { histology (TP) }\end{array}$ & $\begin{array}{l}\text { histology, benign } \\
\text { (FP) }\end{array}$ & $\begin{array}{l}\text { N=Benign } \\
\text { cytology, } \\
\text { benign } \\
\text { histology (TN) }\end{array}$ & $\begin{array}{l}\text { N=Benign } \\
\text { cytology, } \\
\text { neoplastic } \\
\text { histology (FN) }\end{array}$ & $\begin{array}{l}\text { N= Total histologic } \\
\text { follow-up available } \\
\text { (TP+FP+TN+FN) }\end{array}$ \\
\hline $\begin{array}{l}\text { On-Site } \\
\begin{array}{l}\text { Interpretation } \\
\text { No On-Site }\end{array}\end{array}$ & 15 & 6 & 3 & 25 \\
$\begin{array}{l}\text { Interpretation } \\
\text { Nite }\end{array}$ & 15 & 0 & 7 & 8 & 30 \\
\hline
\end{tabular}

TP:True positive cytologic diagnosis

FP:False positive cytologic diagnosis

TN:True negative cytologic diagnosis

FN:False negative cytologic diagnosis

Table 3. Discrepancy between cytologic and histologic diagnoses $(\mathrm{N}=55)$

\begin{tabular}{llcllll}
\hline & $\begin{array}{l}\text { Histologic } \\
\text { follow-up } \\
\text { available }\end{array}$ & Discordance rate & Sensitivity & Specificity & PPV & NPV \\
\hline $\begin{array}{l}\text { On-Site } \\
\begin{array}{l}\text { Interpretation } \\
\text { No On-Site }\end{array}\end{array}$ & 25 & $16 \%$ & $83 \%$ & $86 \%$ & $94 \%$ & $67 \%$ \\
\begin{tabular}{l} 
Interpretation \\
\hline
\end{tabular} & $27 \%$ & $65 \%$ & $100 \%$ & $100 \%$ & $47 \%$ \\
\hline
\end{tabular}

Histological follow-up available: $T=T P+F P+T N+F N$

Discordance rate:FP+FN/T

Sensitivity:TP/TP+FN

Specificity:TN/TN+FP

Positive predictive value on cytology (PPV):TP/TP+FP

Negative predictive value on cytology (NPV):TN/TN+FN

Table 4. Performance characteristics according to the availability of on-site cytopathology ( $N=55$ cases)

In this study, the drop of the inadequacy rate from $21 \%$ without on-site immediate interpretation to $1 \%$ with on-site immediate interpretation is highly statistically significant (p value $<0.0001$ ). The repeat procedure rate dropped correspondingly from $10 \%$ to $5 \%$. It has been shown that EUS-FNA would lose its advantage over the other diagnostic options if its failure rate were over 20\% [44]. The EUS-FNA procedure in various body sites (thyroid, breast, lung, etc. ) generally has a comparable reported failure rate when performed without immediate interpretation, with an average failure rate of $20 \%$ and a maximum of reported failure rate of $32 \%$ [32, 33, 45-47]. In our current study, without immediate interpretation, our inad- 
equacy rate was $21 \%$, a rate at which the procedure may not be cost effective over other diagnostic options. On-site immediate cytology interpretation of EUS-FNA of solid pancreatic lesions thus results in cost savings, reduced intervals between diagnosis and therapeutic intervention, and enhanced patient care.

An important task at the EUS-FNA procedure is representative sampling of the lesion. With on-site immediate microscopic evaluation of part of the sample, an experienced cytologist should be able to assess the cellularity of the sampling and to differentiate gastrointestinal tract carryover material from moderately to poorly differentiated malignant cells. The presence of dense numbers of inflammatory cells, necrotic debris, and fibrous stromal elements provides good evidence that the endosonographer is actually sampling the targeted lesion. In our experience, on-site communication with immediate feedback is invaluable in guiding the next needle pass. Another indispensable value is that immediate evaluation gives the pathologists the best opportunity to triage the sampled material for its optimal use, including sending fresh specimen for flow cytometry analysis for possible lymphoproliferative disease, sending cyst contents for microbiology tests, or chemical analysis for tumor markers, such as amylase, CEA, CA19-9, etc. All those commonly available laboratory tests cannot be performed once the specimen is fixed.

What is the impact of EUS-FNA on-site evaluation in situations of non-solid pancreatic lesions [48-52]? In our daily practice of cytology, EUS-FNA specimens comprise almost half the volume of our on-site immediate assessment service. There are occasions when the aspirated material has presented with an unusual or unexpected, and yet remarkable gross appearance. On-site availability gives us the advantage of observing the gross appearance of freshly aspirated material. With increased experience, we feel these grossly "unusual" aspirates can actually help to raise our suspicion towards a relatively specific diagnosis and triage the material for certain helpful laboratory tests. In our 2008 publication, we conducted 10-year institutional case review and summarized three different patterns of gross appearance of aspirated material from non-neoplastic pancreatic and peri-pancreatic cystic lesions [53].

\subsection{Pattern 1: Grossly yellowish-green pasty material}

Case 1: we encountered two patients who presented with almost identical gross and microscopic findings at EUS-FNA. The first patient was a 52-year-old male with a past medical history of acute gallstone pancreatitis 4 years prior, treated by cholecystectomy. He has had no other episodes of pancreatitis after the surgery. During a workup for his nephrolithiasis, CT scan incidentally identified a $3 \mathrm{~cm}$ unilocular cyst adjacent to the neck and body of his pancreas. Endoscopic ultrasound was requested in order to evaluate this peri-pancreatic cystic lesion. On site, EUS revealed a $3.4 \mathrm{~cm}$ primarily hypoechoic lesion. Aspirated material had an unusual yellowish-green gross appearance with a pasty texture. Microscopically, the smears contain rare squamous cells of gut luminal origin, abundant amorphous material and acellular debris (Figure 1, A). A Hall's stain for bilirubin showed focal staining, suggestive of bile pigment (Figure 1, B). Serum amylase assay was within normal range during this period. In light of the cytological finding and clinical presentation, it was felt that the lesion was most consistent with a small, chronic biloma, which likely developed at the time of his 
cholecystectomy. Follow up CT scan revealed an unchanged cyst and no further evaluation was recommended.

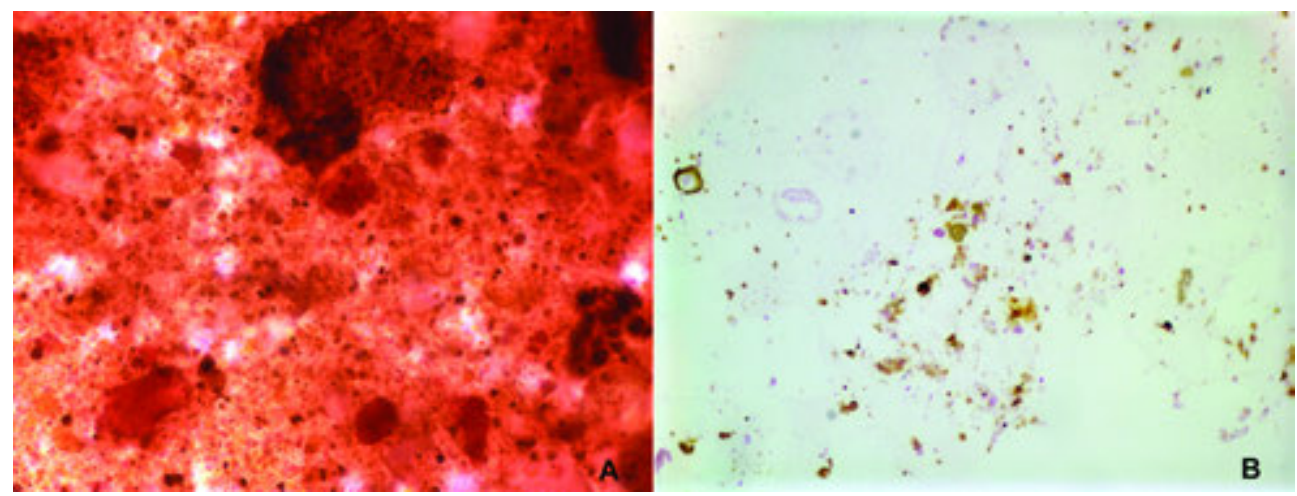

Figure 1. Representative cytologic findings in a case of biloma. Panel A:High-power view showing abundant amorphous material and acellular debris (Papanicolaou stain, 400x). Panel B: A Hall's stain for bilirubin showed focal staining, suggestive of bile pigment (Hall's stain, 400x).

Case 2: the second patient was a 39-year-old male with a history of chronic pancreatitis. During the workup for his intermittent upper abdominal pain, CT scan revealed a $2 \mathrm{~cm}$ hypodense mass off the tail of his pancreas. The patient underwent EUS-FNA twice. Each time EUS revealed a $2 \mathrm{~cm}$ hypoechoic mass off the tail of the pancreas and grossly similar copious yellowish-green material was aspirated and submitted for cytology. Microscopically, both EUS-FNA specimens from this patient revealed almost identical findings as our previous case with abundant bile-stained cyst contents and amorphous debris (Data not shown). No inflammation was present. Concurrent serum CA19-9 assay was within normal limits. Although a specific diagnosis of biloma was not rendered on the original report, findings argue for a benign cystic lesion and a CT follow-up for the stability of the lesion was recommended without further intervention.

\subsection{Pattern 2: Grossly tan-white cheesy material}

Case 3: this was a 42-year-old male with chronic alcohol use and chronic hepatitis B and HIV co-infection. CT scan found a cystic lesion near the pancreatic tail, which had been stable in size. EUS identified a $2.5 \mathrm{~cm}$ complex cystic lesion adjacent to the pancreatic tail with both cystic and solid components. Aspirated material was grossly tan-white in color and semi-solid, cheesy in texture. Most of the material was lost during processing when air-dried or alcoholfixed slides with Diff-Quik or Papanicolaou staining was attempted. Microscopic examination only revealed abundant amorphous degenerate material (Figure 2, A). Given the suspicion that material was dissolved by alcohol, Oil-Red $\mathrm{O}$ stain was performed on air-dried slides and showed variable fat staining (Figure 2, B). Because of the unusual gross appearance, the aspirated material on site was also sent for microbiology (negative findings) and assayed for CEA $(164971 \mathrm{ng} / \mathrm{ml})$, and amylase $(2357 \mathrm{u} / \mathrm{L})$. The significantly elevated CEA level was concerning 
for malignancy. The patient subsequently underwent a distal pancreatectomy and splenectomy. Surgical pathology specimen revealed a cyst present in the adipose tissue adjacent to the pancreas filled with tan-white cheesy material. Microscopically, the cyst is lined by mature keratinizing squamous epithelium and lymphoid tissue with germinal centers surrounding the epithelium, consistent with a lymphoepithelial cyst (LEC) of the pancreas (Figure 2, C \& D). The possibility of a dermoid cyst was also considered due to the evident sebaceous gland differentiation beneath the squamous epithelium. However, the lack of hair follicles and sweat glands and the presence of dense lymphoid tissue with germinal centers were most consistent with the diagnosis of LEC of the pancreas. We presume that the abundant oily material filling the cyst was partially due to the secretion of the sebaceous glands that accumulated intracytoplasmic lipid droplets and produced oily sebum extracellularly. Mixed in with keratin debris, this material could account for the unusual gross-appearance of that tan-white semi-solid atheromatous material aspirated from this patient on EUS-FNA.
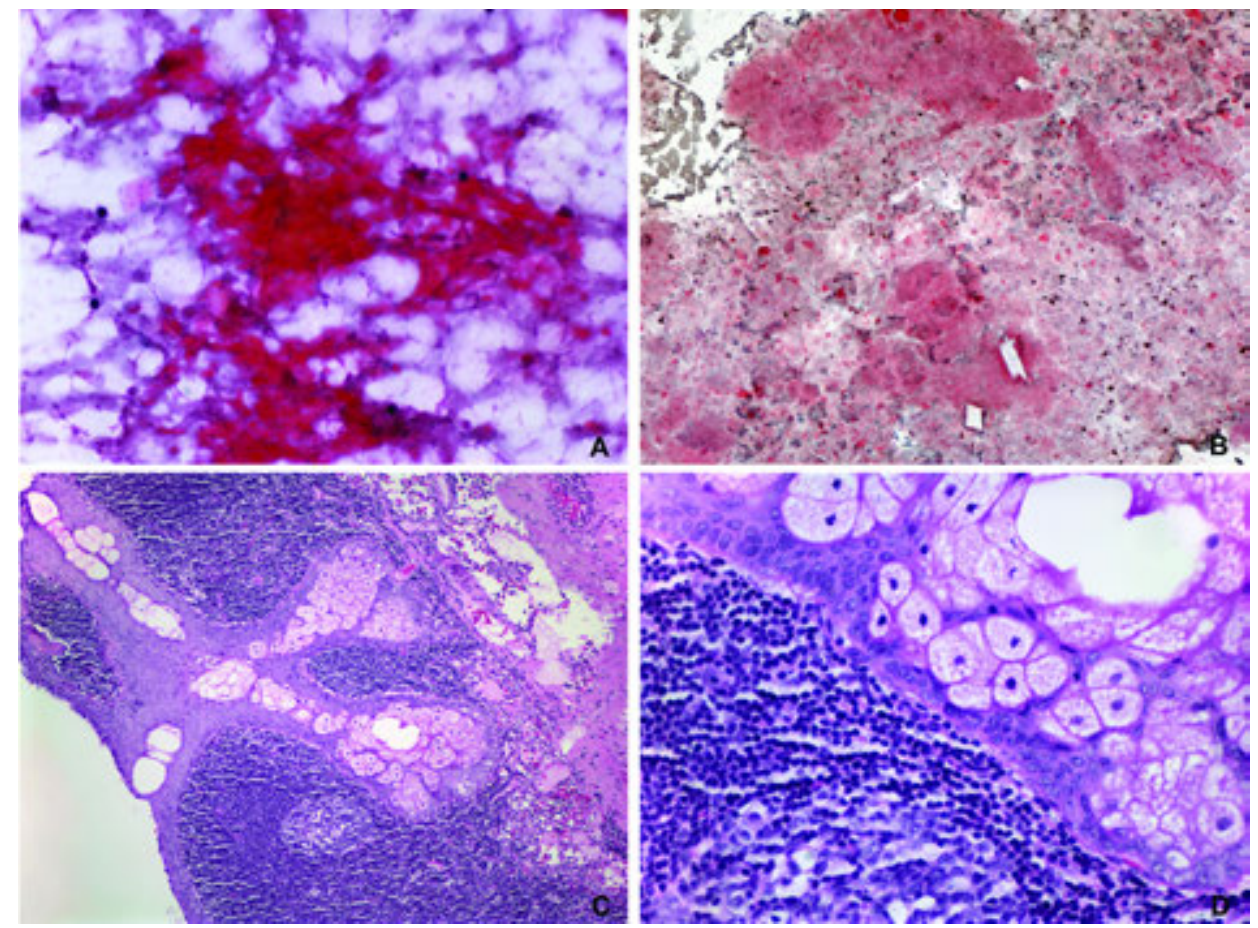

Figure 2. Microscopic findings of a lymphoepithelial cyst of pancreas with sebaceous differentiation. Panel A:Highpower view of cytology aspiration revealing abundant amorphous degenerate material (Papanicolaou stain, 400x). Panel B:Oil-Red O stain on air-dried slides showing focally variable fat staining (Oil-Red O 100x). Panel C:Low-power view of the subsequent surgical pathology specimen revealing a pancreatic cystic lesion lined by mature keratinizing squamous epithelium and lymphoid tissue with germinal centers surrounding the epithelium (Hematoxylin and eosin stain, 100x). Panel D:High-power view showing evident sebaceous gland differentiation of the squamous epithelial lining of the cyst (Hematoxylin and eosin stain, 400x). 


\subsection{Pattern 3: Grossly amber clear fluid, can be darker due to thickness}

Cases 4-6: a computer inventory search from year 1997-2007 at University of Washington allowed us to review three additional cases of lymphoepithelial cysts with cytological diagnosis and follow-up surgical resections. The features of these 3 cases are summarized in Table 5. All those surgical-proven lymphoepithelial cysts showed grossly clear fluid on cytology aspiration with color variation described from light yellow to darker-brown. Available laboratory data showed low amylase and CEA level. The follow-up surgical specimens revealed simple lymphoepithelial cysts with no sebaceous gland differentiation.

Cases 7-8: also included in Table 5 are two cases of surgical-proven pancreatic pseudocyst that presented with grossly similar amber clear to brownish fluid on aspiration while concurrent amylase and CEA level were in the normal range.

\begin{tabular}{|c|c|c|c|c|c|}
\hline Case & 4 & 5 & 6 & 7 & 8 \\
\hline Patient & 35 yо $M$ & 42 yo $F$ & 51 yo $\mathrm{M}$ & 42 yo $F$ & 60 yo $F$ \\
\hline $\begin{array}{l}\text { Surgical } \\
\text { Diagnosis }\end{array}$ & LEC & LEC & LEC & Pseudocyst & Pseudocyst \\
\hline $\begin{array}{l}\text { Clinical } \\
\text { History }\end{array}$ & $\begin{array}{l}\text { Lower } \\
\text { quadrant colic } \\
\text { pain for } 9 \\
\text { months. }\end{array}$ & $\begin{array}{l}\text { Questionable mild } \\
\text { chronic pancreatitis }\end{array}$ & $\begin{array}{l}\text { Choledocolithiasis, s/p } \\
\text { scholecystectomy and } 3 \\
\text { weeks abdominal pain }\end{array}$ & $\begin{array}{l}\text { Alcohol use; 10yr h/o } \\
\text { epigastric pain }\end{array}$ & $\begin{array}{l}\text { Alcohol use; liver } \\
\text { cirrhosis and } \\
\text { chronic pancreatitis }\end{array}$ \\
\hline $\begin{array}{l}\text { Imaging } \\
\text { Study }\end{array}$ & $\begin{array}{l}4.6 \mathrm{~cm} \text { cystic } \\
\text { lesion at the } \\
\text { junction of } \\
\text { pancreatic } \\
\text { head and body }\end{array}$ & $\begin{array}{l}3.4 \mathrm{~cm} \text { well- } \\
\text { circumscribed } \\
\text { radiolucent mass }\end{array}$ & $\begin{array}{l}\text { 4. } 5 \mathrm{~cm} \text { heterogeneous } \\
\text { microcystic mass adjacen } \\
\text { to the uncinate process }\end{array}$ & $\begin{array}{l}3.5 \mathrm{~cm} \text { circumscribed, } \\
\text { theterogenous } \\
\text { pancreatic head mass }\end{array}$ & $\begin{array}{l}3.3 \mathrm{~cm} \text { well } \\
\text { demarcated, } \\
\text { heterogeneous } \\
\text { pancreatic head } \\
\text { mass }\end{array}$ \\
\hline $\begin{array}{l}\text { Gross on EUS- } \\
\text { FNA }\end{array}$ & $\begin{array}{l}\text { Clear light } \\
\text { yellow fluid }\end{array}$ & Clear fluid & No fluid obtained & Serosanguinous fluid & Brownish fluid \\
\hline Cytology Dx & $\begin{array}{l}\text { Cystic contents } \\
\text { and debris, no } \\
\text { epithelium } \\
\text { identified }\end{array}$ & $\begin{array}{l}\text { Rare degenerated } \\
\text { cells and } \\
\text { proteinaceous } \\
\text { debris }\end{array}$ & $\begin{array}{l}\text { Degenerative and } \\
\text { necrotic adipose tissue }\end{array}$ & $\begin{array}{l}\text { Inflammatory cells, } \\
\text { hemosiderin pigment } \\
\text { and debris }\end{array}$ & $\begin{array}{l}\text { Inflammatory cells } \\
\text { and fragments of } \\
\text { fibrous tissue }\end{array}$ \\
\hline Lab Data & $\begin{array}{l}\text { Amylase: } \\
\text { 24-354 U/L; } \\
\text { CEA:25.6-34. } 5 \\
\mathrm{ng} / \mathrm{ml} \\
\text { CA19-9:8 U/ml }\end{array}$ & $\begin{array}{l}\text { Amylase:35 U/L; } \\
\text { CA19-9:12 U/ml }\end{array}$ & Amylase:13-53 U/L; & $\begin{array}{l}\text { Amylase:18-54 U/L; } \\
\text { CEA:3.1 ng/ml } \\
\text { CA19-9:4.5-6.1 U/ml }\end{array}$ & Amylase:12-15 U/L; \\
\hline
\end{tabular}

* Both lymphoepithelial cyst (LEC) and pancreatic pseudocyst can grossly show amber clear fluid upon fine needle aspiration. Fluid can also be thicker in texture and darker in color due to hemorrhagic changes.

Table 5. Salient features of 3 cases of LEC and 2 cases of pancreatic pseudocyst. 
Our experience tells us that being fully aware of the limitations on cytology diagnosis and the high possibility of non-representative sampling of the lesions, cytologists should be ready to reject or classify the specimens as non-diagnostic in many situations of acellular cytological material and thus avoid misleading the clinical decisions with an erroneous diagnosis. On the other hand, based on the individual institute settings and the availabilities of cytopathologists for on-site immediate assessment, cytology diagnosis tends to ignore the gross appearance of the aspirated material and the background material is also often overlooked microscopically, especially in an acellular cytology specimen. Incorporating those gross material observations can sometimes add valuable information towards a pathological diagnosis.

We presented three entities (8 cases) here in an attempt to highlight the diagnostic value of gross appearance in fine needle aspiration cytology that can provide clues to the nature of a pancreatic or a peripancreatic cystic lesion. These three entities: biloma, pancreatic lymphoepithelial cyst and pancreatic pseudocyst, although considered uncommon and not widely represented in the cytology literature, are actually encountered more commonly now with the rapid advance of our imaging and imaging guided-sampling practices. On cytology specimens, those are the lesions that generally produce acellular or sparsely cellular material (not including carryover material from gastrointestinal luminal origin). However by carefully combining the clinical, radiological, laboratory and cytological findings grossly and microscopically, cytology can help lead to or confirm clinical judgments and aid in patient care.

A biloma is an encapsulated bile collection outside the biliary tree. The underlying causes include iatrogenic, traumatic, and spontaneous injury of the biliary tree causing bile leaks. Its diagnosis can be established upon clinical history, imaging studies, and needle aspiration cytology and chemical analysis of the aspirated fluid. The symptomatic biloma if left untreated may result in significant morbidity and mortality. However, non-surgical intervention is considered the first choice of treatment for biloma, especially in many asymptomatic situations. Alternatively symptomatic biloma may be treated successfully with interventional radiologic techniques instead of open surgery [54, 55]. It was recently reported that endoscopic ultrasound-guided fine-needle aspiration of an infected biloma, together with endoscopic biliary stent placement, resulted in complete resolution of a patient's biloma [56]. Thus, cytological diagnosis of biloma upon EUS-FNA can help a great deal in managing this potentially complex problem.

A wide variety of cystic lesions can arise within or adjacent to the pancreas. They can be generally placed into non-neoplastic and neoplastic categories. The non-neoplastic cystic lesions can be both congenital and acquired. EUS-FNA has emerged as the primary choice for obtaining diagnostic material on pancreatic cystic lesions. Aspirated cystic fluid analysis for pancreatic enzymes, tumor markers, and fluid viscosity can be of great help in the differential diagnosis. Non-neoplastic cysts generally are high on amylase level and low on tumor markers (CEA, CA 19-9) while these tumor markers are generally elevated in malignant cystic neoplasms, but low in non-neoplastic or benign neoplastic cysts. Having said that, exceptions do occur and no standardized values exist among institutions. On cytology speci- 
men, neoplastic cystic lesions usually produce a more cellular aspirate compared to nonneoplastic cysts if appropriately sampled.

The acquired non-neoplastic pancreatic cysts include dermoid cysts, LECs and pseudocysts. Both dermoid cysts and LECs are squamous-lined non-neoplastic cysts. LECs are benign cystic lesions [57] seen predominantly in males, in the fifth to sixth decades of life. They may be unilocular or multilocular. The cyst contents may vary from serous to cheesy/casseousappearing material depending on the degree of keratin formation. Microscopically, the cysts are lined by well-differentiated stratified squamous epithelium, which may or may not have prominent keratinization. In some areas, the lining may appear more transitional, and in others, flat, cuboidal, or focally denuded. The squamous epithelium is surrounded by a band of dense lymphoid tissue composed of mature T-lymphocytes with intervening germinal centers formed by B cells. The representative aspirate findings are non-specific, showing a mixed population of lymphocytes, histiocytes in a background of keratin debris and proteinaceous debris. Squamous lining cells may be seen. The occurrence of sebaceous glands in LEC of pancreas is well documented [58]. It is unclear whether the florid sebaceous glandular differentiation correlates with the exceedingly elevated CEA and amylase level in our patient. LECs of the pancreas do not appear to be associated with any autoimmune conditions, human immunodeficiency virus infection, lymphoma, or carcinoma. All of these lesions have been documented to occur in their salivary gland counterparts [59]. Dermoid cysts are also rare in the pancreas region. They are reported in younger patients ( $2^{\text {nd }}-3^{\text {rd }}$ decades). The presence of sebaceous glands or hair follicles and absence of closely associated lymphoid tissue is more typical for dermoid cysts and differentiate them from LECs.

Pancreatic pseudocysts account for the vast majority (75-90\%) of pancreatic cysts [60]. Pseudocyst lacks an epithelial lining. It develops when a focus of peri-pancreatic fat necrosis is resorbed, producing a debris-filled space rich in pancreatic exocrine enzymes. It is in general composed of an inflammatory fibrous capsule surrounding a region of necrosis. However, the pathologic findings may vary depending on the stage of the process. The cyst contents, originally necrotic fat, transform into a mixture of necrotic cells, enzymes, scavenger cells, cholesterol clefts and sometimes neutrophils. The tissue that surrounds the necrotic material first produces granulation tissue, and eventually becomes a fibrotic pseudocapsule. FNA usually yields clear to dark brown fluid, which often but not always (as in our cases) shows elevated amylase level on fluid analysis. Aspirate smears are again non-specific and composed of granular necrotic debris and mixed inflammatory cells [61]. A clinical history of pancreatitis and confirmatory gross evidence of pancreatitis on imaging should confirm the diagnosis. The diagnosis of pseudocyst on cytology should be considered one of exclusion.

\section{Aim 3: Application of immunocytochemistry (ICC) studies in EUS- FNA obtained cytology material}

When applying ancillary techniques in cytologic specimens, cytopathologists often encounter the difficulties of limited material, lack of negative or positive controls or lack of internal 
controls. On the other hand, the presence of internal control material can sometimes add confusion rather than reassurance in ICC-stained material. Nevertheless, by carefully and strategically using the cytology specimen, immunocytochemical studies are often achievable with limited aspiration material. We have used some of the techniques that have been described by others, such as immunostaining over Papanicolaou-stained monolayer slides; applying different antibodies to different areas of one smear slide; or making cell block preparations whenever possible. When unstained material is not available and no cell block is initially prepared, Dr. V. Grieco and her colleagues at Harborview Medical Center, Seattle, Washington, have used a scraped slide technique that transfers smear material on Papanicolaou stained slides into paraffin embedded cell blocks. The cell block can then be used for ICC with appropriate controls. If successful, this may avoid the necessity of obtaining additional tissue. We have routinely used this scraped cell block technique in our daily practice as well as in research projects. We hereby briefly discuss our mucin study project with archival cytology material from 1997-2007 at University of Washington, presented at Digestive Disease Week [62]. Schema of Scraping Technique is illustrated in Figure 3: scraping the material from rehydrated direct smear slides into a cell block preparation.

\section{Schematic of scraping technique}

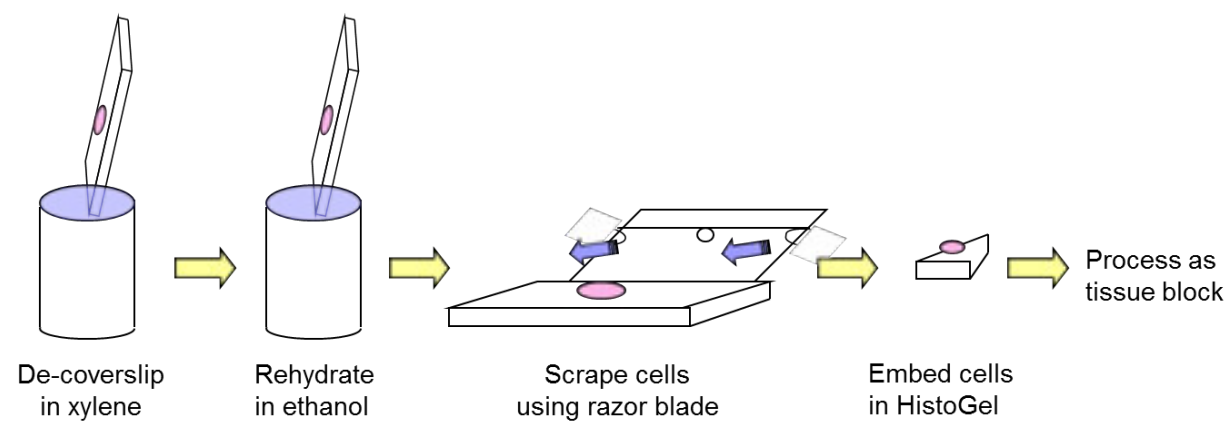

Figure 3. Schema of Scrapped Cell Block Technique:Papanicolaou-stained cellular direct smears are placed in xylene, coverslip removed, and re-hydrated in sequentially graded ethanol to tap water. The cellular material is then scraped from the glass slides using a razor blade, embedded in Histogel and processed with routine cell block preparation. 
Cytology diagnosis of mucin-producing pancreatic neoplasms including mucinous noncystic carcinoma (colloid carcinoma), mucinous cystic neoplasm, and intraductal papillarymucinous neoplasm (IPMN) is important because of the speculation that disruption of the integrity of these mucinous tumors by an incisional biopsy may cause dissemination of tumor cells with mucin and worsen the prognosis. Mucin-detection is not always an easy task on EUS-FNA specimen. Reactive/inflammatory pancreatitis can cause dilated ducts andpseudocyst formation with proteinaceous precipitate that can be mistaken as mucinous material. Sheets of carry-over gastric foveolar cells can mimic cells from mucinous neoplasia [ 63-67]. By applying conventional cytochemistry including PAS (periodic acid-Schiff reaction), PASD (PAS with diastase), alcian blue and mucicarmin, in conjunction withmucin protein (MUC1, MUC2) immunostaining on surgical-proven cytology specimens, this study aims at selecting a practical diagnostic tool to enhance the diagnostic accuracy of detecting mucin-producing pancreatic neoplasms.

Studied material include: 1) Bench FNA specimens performed on autopsy or surgical-obtained normal tissue that are likely to be carried-over during an endoscopic procedure including pancreas, gastric body, pylorus and duodenum; 2) EUS-FNA (with scraped cell block preparation by scraping archival smears into a cell block), along with subsequent surgical specimens on mucinous cystadenoma, borderline mucinous cystic neoplasm, IPMN, colloid carcinoma and ductal adenocarcinma with mucin production; 3) Non-mucin producing lesions including solid pseudopapillary tumor and chronic pancreatitis with dilated duct. Our data demonstrate that mucicarmin is very insensitive in detecting mucin production. We are unable to show reliable mucicarmin staining on both surgical and cytology specimen of IPMN(Figure 4, Panel D-F) as well as mucinous cystic neoplasia cases. MUC1 and MUC 2 immunostains do not consistently pick up mucin production by pancreatic neoplasia on cytology specimens either. In contrast, PAS/PAS-Diastase are a reliable and sensitive marker to stain background mucin material and mucin-producing epithelial cells on cytology, yet specific enough to distinguish proteinaceous precipitate in a pancreatitis case (Figure 4, Panel A-C, precipitate in a dilated duct that was mistaken as possible mucinous material on cytology). The results have directed our daily practice on the use of mucin stains on cytologic diagnosis of pancreatic mucinous neoplasia.

Concomitant use of ICC can greatly enhance the diagnostic accuracy on cytology specimens, especially when it comes to the diagnostic entities invariably requiring immunophenotypic identification, such as in the diagnosis of pancreatic endocrine neoplasia (PENs) [68-72]. However, due to the initial unanticipated nature of the lesion, lack of cytopathologist on site or difficulties of the procedure, sufficient aspirate/biopsy material for cellblock preparation is not always available. By using the scraped cell block technique, a select panel of immunocytochemical studies can be achieved to aid in the diagnosis of PEN. Using the aforementioned scraped cell block technique, figure 5 shows strong expression of the neuroendocrine immuno-marker, chromogranin, by the neoplastic cells. Figure 6 shows neoplastic cells stained positively with the neuroendocrine marker, synaptophysin by directly applying the antibody onto a Papanicolaou-stained charged monolayer slide. 
PANCREATITIS WITH DILATED DUCT

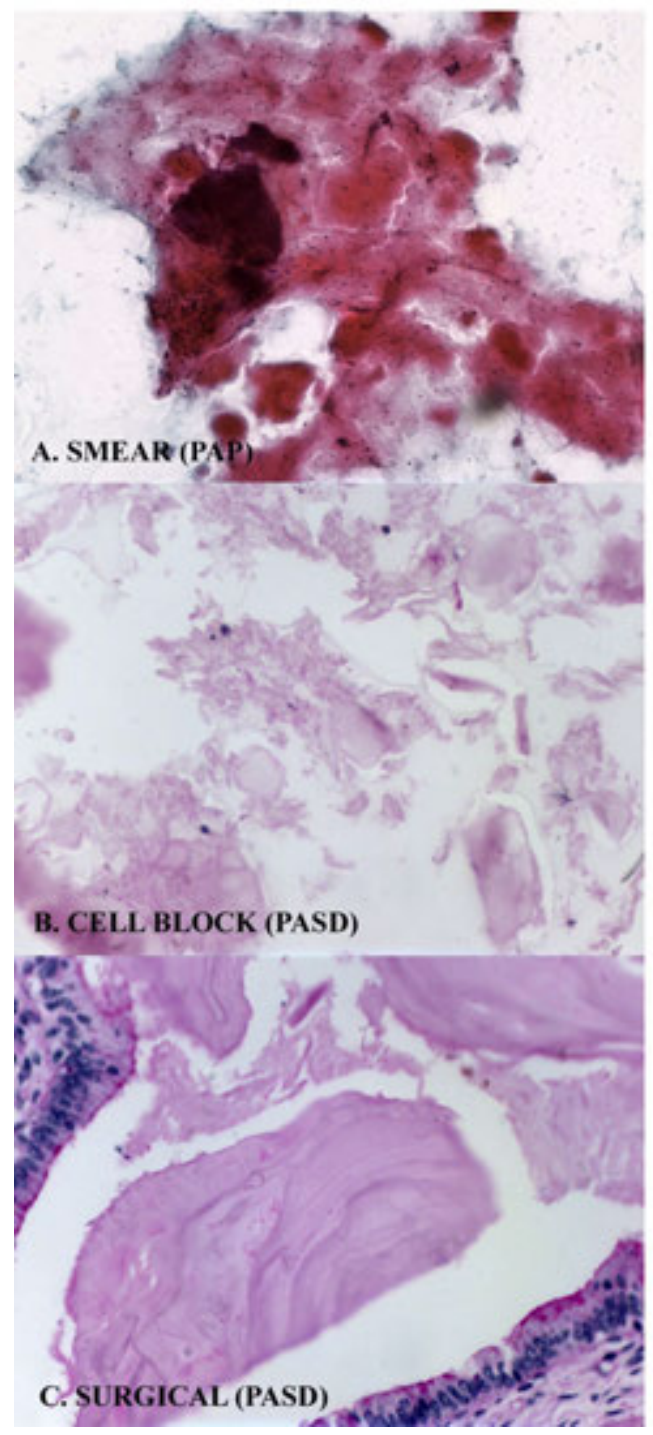

IPMN

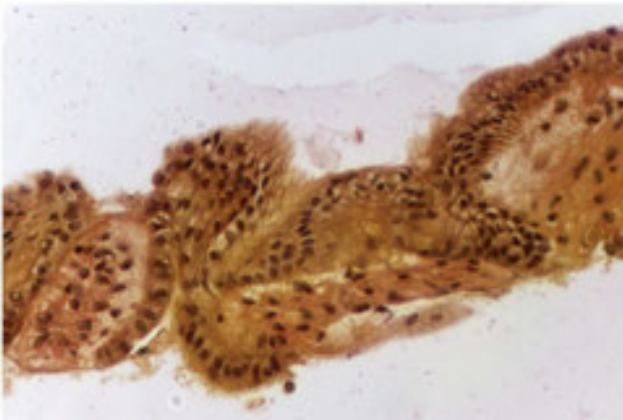

D. CELL BLOCK (MUCICARMIN)

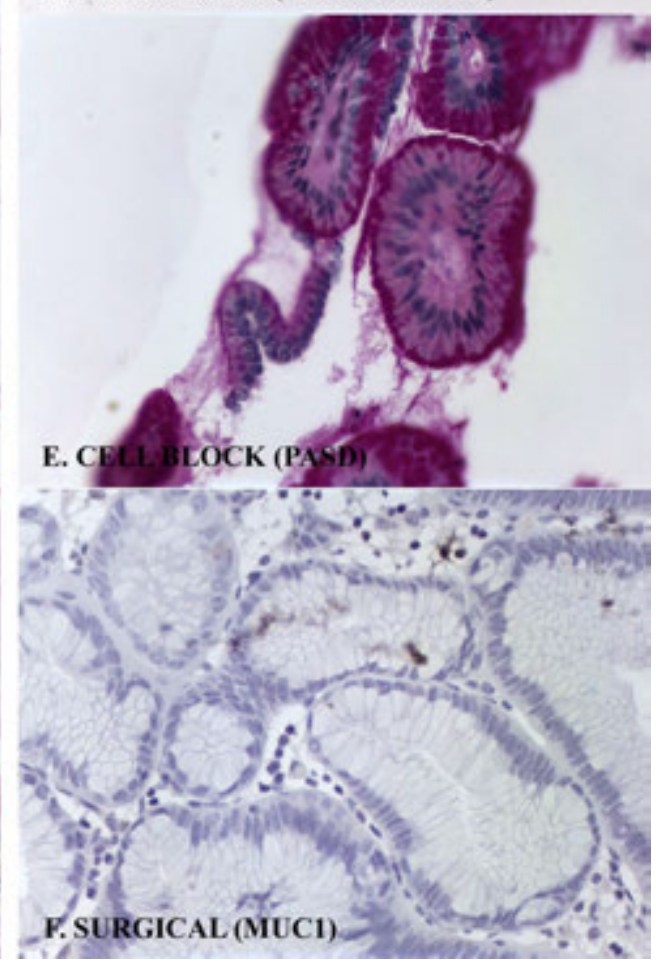

Figure 4. In a case of IPMN, with negative staining for mucicarmine and MUC1, PASD highlighted the mucinous neoplastic cells uniformly (panel D-F). Negative PASD staining in a pancreatitis case with precipitate in a dilated duct that was mistaken as possible mucinous material on cytology initially (panel A-C). 


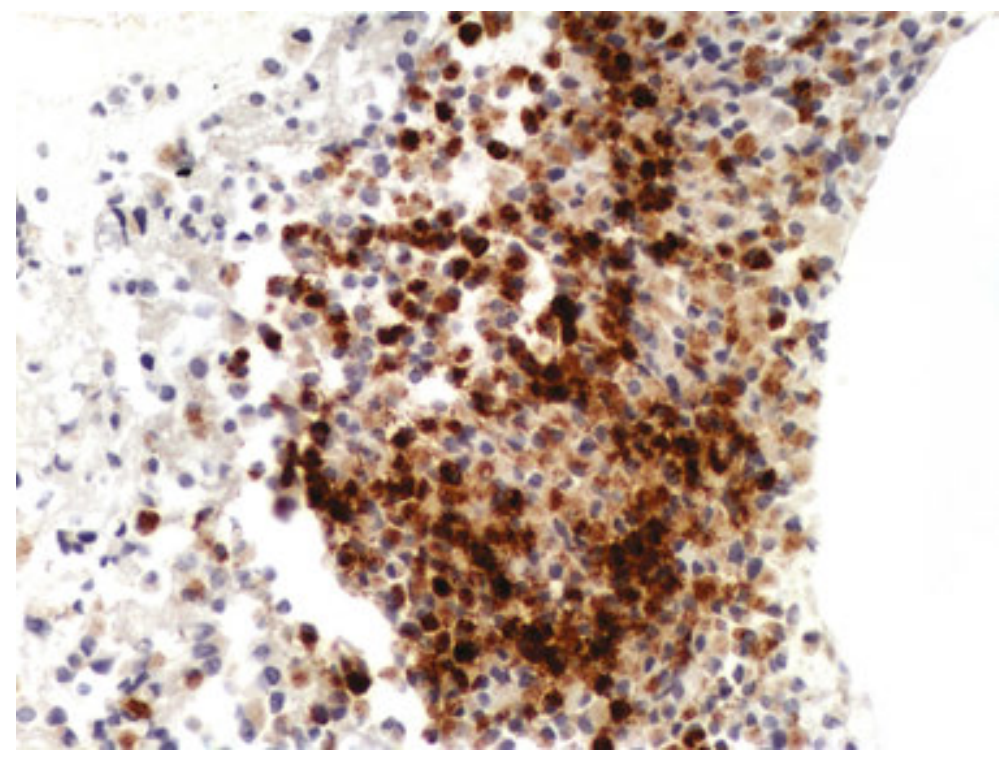

Figure 5. Immunocytochemical stain on a scraped cellblock section displaying strong expression of neuroendocrine marker, Chromogranin by the neoplastic cells (Scraped material for cell block preparation, 400x).

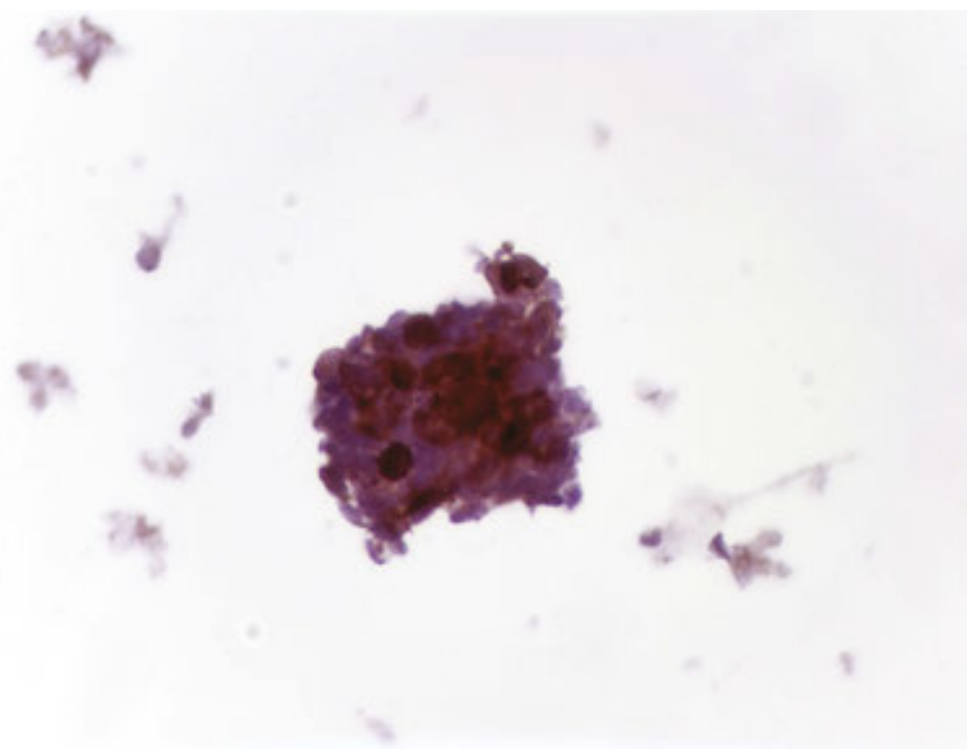

Figure 6. Neoplastic cells on a monolayer slide stained positively with neuroendocrine marker, synaptophysin antibody (400x) 
Before leaving this section, it should also be stated that in cytology, as in surgical pathology, the light microscopic appearance of the tumor is more important than a particular staining result and that immunocytochemistry should be used for confirmation of the cytomorphological diagnosis. Be aware of that the staining of cytology specimens is often focal and sometimes difficult to interpret, because of various factors, including limited material, high background staining, and the presence of three-dimensional clusters with non-specific staining and edge artifact. A combined clinical, radiographic and pathologic approach should always be emphasized in rendering each diagnosis.

\section{Aim 4: EUS-FNA as a source of material for molecular studies}

We are at the beginning of the era of clinical application of molecular probes to assess genetic alterations. Many assays have become clinically available in identifying genetic alterations that serve as prognostic markers and therapeutic targets. EGFR expression in head and neck cancers, non-small cell lung carcinomas, colon cancers, and recently in pancreatic cancers [73-82]; microsatellite instability tests in colon cancer serve as prognostic marker, therapeutic predictive marker and screening test for Lynch syndrome [83-88] are among the most studied areas. Immunodetection of molecular markers on cytology specimen, especially in cancer staging for metastatic disease will be playing a major role as a guide for moleculartargeted therapy. EGFR expression has now been routinely assessed on cell block cytology specimens by many of the commercial or academic laboratories. A prominent example in this regard is FNA diagnosis of thyroid nodules. Given that the cytology reports on thyroid FNA diagnoses are often indeterminate or suspicious, the potential use of diagnostic molecular markers as adjunct methods for cytologic diagnosis appears to be among the most promising area of research [89-98]. Fluorescent (FISH) and chromogenic (CISH) in situ hybridization have recently become part of the diagnostic armamentarium of breast pathologists. HER2 gene amplification testing by FISH and/or CISH has become an integral part of the diagnostic workup for patients with breast cancer [99-105 ]. FISH or CISH is now used in FNA material with success in many situations, including HER2 assessment in FNA with excellent correlation with the histologic specimens [106-108 ]. Many other applications, such as $\mathrm{N}$-myc amplication on FNA from neuroblastomas $[109,110]$ and potential use of multiplex FISH for detection of recurrence of transitional carcinomas on urine specimens [111-114] are also well documented molecular tests using cytology specimens.

Compared to paraffin-embedded tissue, cytology specimens offer the advantage of disaggregated, intact cells, with fewer problems associated with tumor cell homogenization. FISH or CISH probe for diagnosis should be expected to be detected more accurately in cytologic specimen as it contains whole cells and whole nuclei. For the patient, the advantages include low cost, prompt access and the avoidance of surgery.

In carcinogenesis, the majority of molecular alterations occur prior to progressive tumor growth. It has been well documented that resection of small (early) pancreatic tumors and tumors of low histological or cytological grade and stage are correlated with improved survival. 
It is, therefore, important to identify these tumors in their early stages. DNA methylation changes are an early event in carcinogenesis and are often present in the precursor lesions of various cancers. Dr. N. Kiviat's lab at Harborview Medical Center, Seattle, Washington, has published extensively in constructing a panel of candidate hypermethylated genes with optimal sensitivity and specificity as a potential screening tool for cervical neoplasia, ovarian carcinoma and lung cancer [115-118]. In collaboration with Dr. N. Kiviat's lab, we performed molecular tests on EUS-FNA of pancreatic lesions in the form of remains in liquid-based preparation, together with bench-performed mock FNA from normal pancreas obtained through Harborview trauma center. We preliminarily tested the hypothesis that a panel of hypermethylated genes with high sensitivity and specificity for pancreatic adenocarcinoma might increase the accuracy of diagnosis of FNA and brush cytology on pancreatic cancer.

Method Excess material from five pancreatic FNAs, three pancreatic duct brushings and nine bile duct brushings from patients who subsequently had histologic evaluation upon surgery were studied. Genomic DNA was isolated from residual cytology brushing sample pellets using QIAamp Blood DNA isolation kit and methylation status of seven genes, was accessed using MethyLight assay after bisulfite conversion [115]. These genes were reported to be frequently methylated in other cancers, including RASSF1A (Ras association domain family 1A gene), UCHL1 (ubiquitin carboxyl-terminal esterase L1), APC (adenomatosis polyposis coli), IGSF4 (also called CADM1, cell adhesion molecule 1), CDH13 (cadherin 13), CCND2 (cyclin D2), and CDKN2A (cyclin-dependent kinase inhibitor 2A, p16). Primers and probes for these genes are listed in Table 6. Sample adequacy after bisulfite conversion was determined by amplification of $\beta$-actin gene (ACTB). The percentage of methylated reference (PMR) for each gene was calculated as before [115]. The methylation status of a sample was categorized in two ways: as having any methylation present (PMR $>0)$ and as having high levels of methylation (PMR $\geq 4 \%$ ), as previously described [115].

\begin{tabular}{|c|c|c|c|}
\hline Gene & Forward primer (5'-3') & Probe $\left(5^{\prime}-3^{\prime}\right)$ & Reverse primer (5'-3') \\
\hline ACTB & TGGTGATGGAGGAGGTTTAGTAAGT & $\begin{array}{l}\text { 6FAM- } \\
\text { ACCACCACCCAACACACAATAACAAACACA- } \\
\text { TAMRA }\end{array}$ & AACCAATAAAACCTACTCCTCCCTTAA \\
\hline APC & TTATATGTCGGTTACGTGCGTTTATAT & 6FAM-CCCGTCGAAAACCCGCCGATTA-TAMRA & GAACCAAAACGCTCCCCAT \\
\hline CCND2 & CGTGTTAGGGTCGATCGTGTT & 6FAM-ACTACGATAAAATCGCCG-MGB & CTCGCCAAACTTTCTCCCTAAA \\
\hline $\mathrm{CDH} 13$ & GATTTTTGGGTTCGGAATGATTT & 6FAM-TTTTCGTCGTCGCGATC-MGB & ATCGCCCGACACGAACAA \\
\hline CDKN2A & TGGAGTTTTCGGTTGATTGGTT & 6FAM-ACCCGACCCCGAACCGCG-TAMRA & AACAACGCCCGCACCTCCT \\
\hline IGSF4 & AGGGAGCGAGGTTTTTCGA & 6FAM-CGAACCCAACCCGAC-MGB & ACGAAATCCGAACAAACCAATC \\
\hline RASSF1 & TAGGTTTTTATTGCGCGGTTTT & 6FAM-CGCGAACCGAACGAA-MGB & TACTTCGCTAACTTTAAACGCTAACAA \\
\hline UCHL1 & TCGCGAAGATGTAGTTTAAGTCGAT & 6FAM-ACGCTCACCTCGAAAT-MGB & CGCGCTCTCCGAATAACG \\
\hline
\end{tabular}

Table 6. Primers and probes for MethyLight assays 
Results A total of 17 samples were available for examination. No DNA remained in one bile duct brushing after preparation of smears for microscopic examination. Thus, 16 samples, 12 malignant and 4 benign (by histology) were evaluated. On microscopic examination of the FNA and brush cytologic specimens, 8 of the 12 samples which were later shown to be malignant (on biopsy) were classified as "suspicious" for malignancy while four were called definitively "positive" for malignancy by FNA or brush. The remaining four cases were histologically benign. Two of these cases were called "negative" on microscopic examination of the FNA or brush specimen, one was classified as "atypical" and one as "suspicious for malignancy". The distribution of aberrantly methylated genes of interest among the benign and malignant lesions is presented in Table 7.

\begin{tabular}{|c|c|c|c|c|c|c|c|c|}
\hline \multirow{2}{*}{ Gene } & \multicolumn{4}{|c|}{$\begin{array}{l}\text { Any Methylation } \\
\text { (PMR>0\%) }\end{array}$} & \multicolumn{4}{|c|}{$\begin{array}{l}\text { High Methylation } \\
\quad \text { (PMR } \geq 4 \%)\end{array}$} \\
\hline & & $\begin{array}{l}\text { Malignant } \\
\quad(n=12)\end{array}$ & & $\begin{array}{c}\text { Benign } \\
(n=4)\end{array}$ & & $\begin{array}{l}\text { Malignant } \\
\quad(n=12)\end{array}$ & & $\begin{array}{c}\text { Benign } \\
(n=4)\end{array}$ \\
\hline UCHL1 & 9 & $(75 \%)$ & 1 & $(25 \%)$ & 6 & $(50 \%)$ & 0 & $(0 \%)$ \\
\hline APC & 7 & $(58 \%)$ & 1 & $(25 \%)$ & 3 & $(25 \%)$ & 0 & $(0 \%)$ \\
\hline RASSF1 & 3 & $(25 \%)$ & 0 & $(0 \%)$ & 2 & $(17 \%)$ & 0 & $(0 \%)$ \\
\hline IGSF4 & 3 & $(25 \%)$ & 0 & $(0 \%)$ & 1 & $(8 \%)$ & 0 & $(0 \%)$ \\
\hline CDH13 & 8 & $(67 \%)$ & 0 & $(0 \%)$ & 3 & $(25 \%)$ & 0 & $(0 \%)$ \\
\hline CCND2 & 10 & $(83 \%)$ & 4 & $(100 \%)$ & 8 & $(67 \%)$ & 2 & $(50 \%)$ \\
\hline CDKN2A & 0 & $(0 \%)$ & 0 & $(0 \%)$ & 0 & $(0 \%)$ & 0 & $(0 \%)$ \\
\hline CDH13 or RASSF1 & & $(75 \%)$ & & $0 \%)$ & & & & \\
\hline \multicolumn{5}{|l|}{ UCHL1, CDH13, or } & \multirow{2}{*}{\multicolumn{2}{|c|}{$(67 \%)$}} & & \multirow[t]{2}{*}{$(0 \%)$} \\
\hline RASSF1 & & & & & & & & \\
\hline
\end{tabular}

Table 7. Promoter Hypermethylation by Histologic Diagnosis

Methylation of three different genes (RASSF1, IGSF4, and CDH13) was present at some level in malignant but not benign samples, and methylation of two other genes (UCHL1 and APC) was present at a higher frequency in the majority of malignant samples but was present in only one of four benign samples. For two genes, methylation was either present in nearly all samples, regardless of histologic diagnosis (CCND2) or was not present in any samples (CDKN2A). For five genes, high levels of methylation (PMR $\geq 4 \%$ ) were present in malignant cases but were not detected in any of the benign samples. We next identified the combination of genes with the highest sensitivity and specificity for pancreatic cancer. 
When any level of methylation was considered as positive, aberrant methylation of CDH13 or RASSF1 provided optimal sensitivity and specificity for cancer, being present in $75 \%$ of malignant and $0 \%$ of benign specimens (Table 7). Considering high levels of methylation $(\mathrm{PMR} \geq 4 \%$ ), the most sensitive and specific combination of methylated genes was UCHL1, CDH13 and RASSF1 which were positive in $67 \%$ of malignant but $0 \%$ of benign specimens (Table 7). Next we examined, whether detection of aberrantly methylated genes might increase our ability to accurately classify FNA and brush specimens as "positive" or "negative" for malignancy. Using this approach, FNA and brush specimens were classified as "Positive for malignancy" if either cells with malignant morphologic changes or any level of methylation of CDH13 or RASSF1 was present (Table 8). Specimens were called "Negative for malignancy" if the cells were morphologically normal or cells were atypical or suspicious by morphology but there was no evidence of aberrant methylation of either CDH13 or RASSF1. This algorithm detects $83 \%$ of malignant samples while maintaining $100 \%$ specificity. We are aware that an independent sample set is necessary to appropriately test this algorithm; however, this pilot data suggests that a panel of hypermethylated tumor suppressor genes might be useful in distinguishing malignancy from benign pancreatic lesions. A similarly sensitive and specific algorithm combining cytologic morphology and a panel of genes methylated at high levels (PMR $\geq 4 \%$ of UCHL1, CDH13 and/or RASSF1 present) was also developed.

\begin{tabular}{lcc}
\hline Final Diagnosis & $\begin{array}{c}\text { Malignant } \\
(\mathbf{n}=\mathbf{1 2})\end{array}$ & $\begin{array}{c}\text { Benign } \\
(\mathbf{n}=\mathbf{4})\end{array}$ \\
\hline POSITIVE & $4(33 \%)$ & $0(0 \%)$ \\
\hline morphology consistent with malignancy & $9(75 \%)$ & $0(0 \%)$ \\
\hline Or aberrant methylation of CDH13 & $10(83 \%)$ & $0(0 \%)$ \\
\hline Or aberrant methylation of RASSF1 & $2(50 \%)$ \\
\hline NEGATIVE & $4(100 \%)$ \\
\hline Negative morphology or & \\
\hline Atypical or suspicious cell morphology but no aberrant methylation of CDH13 or RASSF1 & \\
\hline
\end{tabular}

Table 8. Cytology or Any Methylation (PMR>0\%) vs. Histology

Conclusions. Although the present study was limited by the fact that we were not able to test these algorithms in an independent sample, it appears that FNA and brush cytologic specimens can be more accurately classified as positive or negative for pancreatic cancer by including methylation analysis of tumor suppressor genes.

The variable mixture of tumor cells and normal cells is a major challenge when it comes to the molecular analysis of diagnostic or therapeutic targets in cytologic specimens. Cytologists are needed to play an active role in the adoption and application of molecular techniques, since we are able to interpret the results in the light of cytological morphology. Our 
pilot data holds promise for further research to conduct a genome wide search for additional aberrantly methylated genes with high sensitivity and specificity for pancreatic cancer and which are not methylated in other tissues (such as colon, liver, stomach, duodenum) which can be frequently or incidentally present as carry-over material in FNA and brush specimens from pancreatic lesions.

\section{Aim 5: Achieving the full value of EUS-FNA with an integrated approach: A EUS-FNA case study}

A 67-year-old woman was found to have a large retroperitoneal mass of uncertain etiology. The mass appears to invade the inferior vena cava and renal vein. Two prior attempts of CT and ultrasound guided biopsy were non-diagnostic due to the biopsy specimen consisting predominantly of necrotic tissue. Endoscopic ultrasound and enteroscopy were requested to re-evaluate the lesion and re-attempt biopsy.

In the initial effort of EUS-FNA, rare clusters of neoplastic cells having round nuclear contour, mild nuclear crowding and overlapping, vesicular chromatin pattern, and distinct nucleoli are noted in a background of extensive necrosis and blood. Fresh material sent for flow cytometry analysis contained an abnormal CD56- and EpCAM-positive population. Abnormal B or T cell populations were not identified. A cytologic impression was issued as: Positive for neoplasm with features suggestive of neuroendocrine origin. Before implementing chemotherapy as neuroendocrine tumor, our astute clinician ordered indiumIII octreotide scan for clinical correlation and found no evidence of focal radiotracer uptake in the abdominal mass. The diagnosis was subsequently felt not sufficiently conclusive for therapy as neuroendocrine neoplasia. A repeat biopsy was requested. During the second attempt of EUS-FNA, there was extrinsic appearing compression at the second, third, and fourth portions of the duodenum with no evidence of mucosal lesions or ulcerations. A large (greater than $12 \mathrm{~cm}$ ) heterogeneous hypoechoic mass lesion was identified adjacent to the head and neck of the pancreas. One component of the mass appeared to be cystic (Figure 7, panel A, with needle inside the cystic area), and a more solid component was also identified (Figure 7, panel B). The former was sampled with FNA, the latter with a core biopsy. Nine total FNA passes were obtained with on-site immediate interpretation:

Pass 1 (core biopsy):Blood and necrotic material, non-diagnostic.

Pass 2 (core biopsy):Blood, necrotic material and sheets of bland epithelium. Additional diagnostic material requested.

Pass 3 (needle aspirate):Chiefly blood with atypical cells present.

Pass 4 (needle aspirate):Chiefly blood.

Pass 5 (needle aspirate):Chiefly blood.

Pass 6 (needle aspirate):Placed directly into saline. 
Pass 7 (needle aspirate):Atypical cells present, defer to permanents.

Pass 8 (needle aspirate):Atypical cells present, defer to permanents.

Pass 9 (needle aspirate):Placed directly into saline for cell block preparation.

Many clusters of viable cells were obtained during the second attempt of EUS-FNA, displaying cytological features including three dimensional clusters, loose monolayer and individual monotonous cells, microfollicular pattern and nuclear grooves (coffee bean-like nuclei). The tumor cells are uniform and lack nuclear hyperchromasia and pleomorphism (Figure 7, panel C-E). Given the ample material obtained, a cell block was prepared and a more complete panel of antibodies for ICC was able to be performed, with the following results (19 antibody stains performed on cytology specimen, figure 7, panels E, F):

\begin{tabular}{|c|c|}
\hline Antibody & Results \\
\hline AE1/AE3 & Positive, focally \\
\hline CALRETININ & Positive \\
\hline CD10 & Negative \\
\hline CD34 & Negative \\
\hline CD56 & Positive, uniformly \\
\hline CD68/KP-1 & Negative \\
\hline $1 \mathrm{~A} 4$ & Positive, focally \\
\hline DESMIN & Negative \\
\hline S100 & Negative \\
\hline CHROMOGRANIN & Negative \\
\hline SYNAPTOPHYSIN & Negative \\
\hline C-KIT & Negative \\
\hline INHIBIN & Positive, uniformly \\
\hline MELAN A & Negative \\
\hline CD45 (T200) & Negative \\
\hline EMA & Negative \\
\hline NSE & Positive, focally \\
\hline ER (clone 1D5) & Negative \\
\hline ER (clone SP1) & Positive \\
\hline
\end{tabular}

Table 9. 

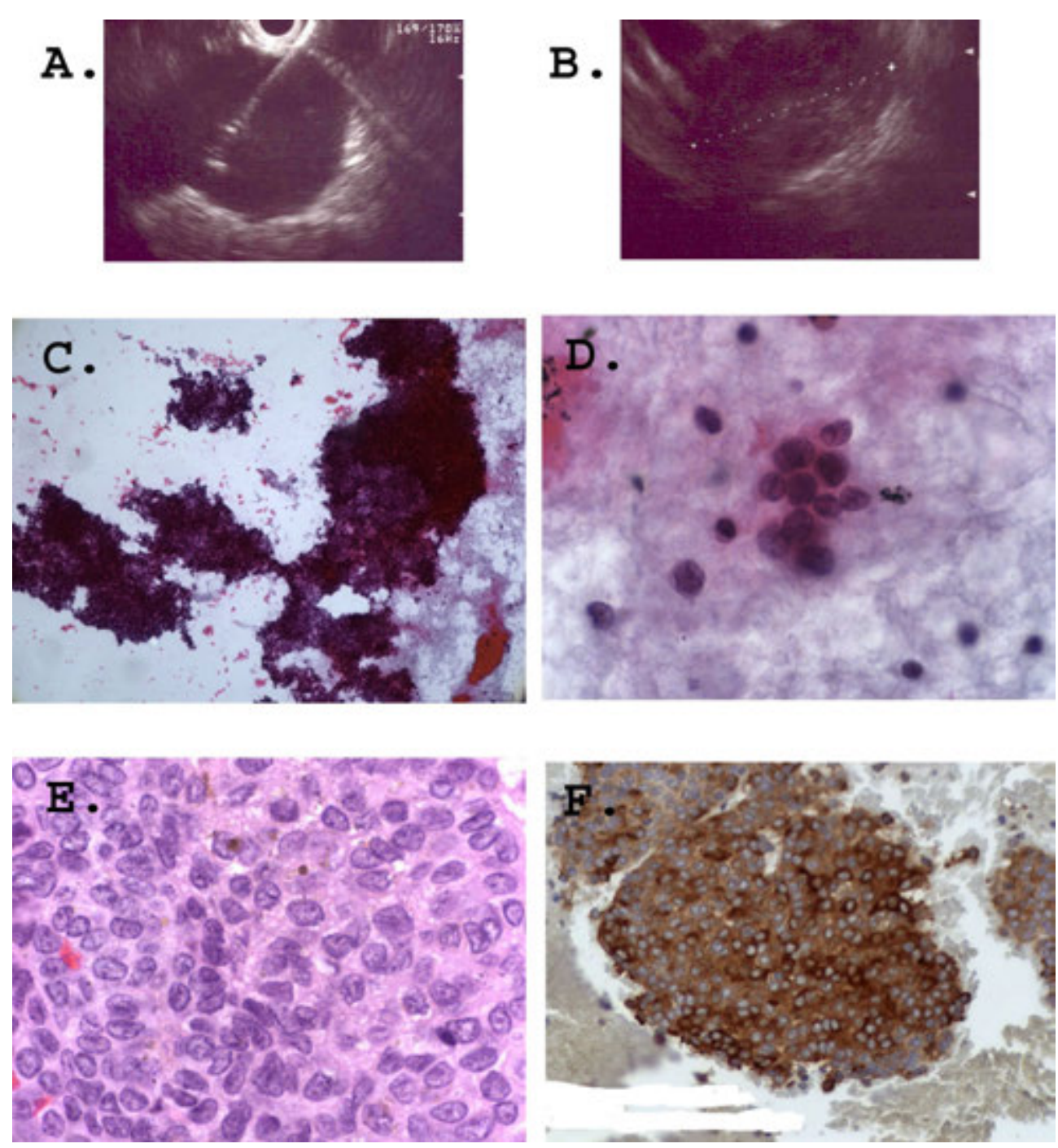

Figure 7. EUS-FNA diagnosis of granulosa cell tumor. A heterogeneous hypoechoic mass lesion identified by EUS. One component of the mass appearsto be cystic (panel A, with needle inside the cystic area); A more solid component (panel B); Ample viable material obtained on repeat EUS-FNA (panel C, Pap smear $100 \mathrm{x}$ ); Cytomorphology of neoplastic cells on smear (panel D, oil immersion, $1000 \mathrm{x}$ ); Cytomorphology of neoplastic cells on cell block section (panel E, oil immersion, $1000 \mathrm{x}$ ); Application of inhibin antibody on cell block section (panel F, $400 \mathrm{x}$ ).

The combined cytologic and immunophenotypic profile leads to the following final diagnosis:

Retroperitoneal mass, endoscopic ultrasound-guided FNA: Consistent with metastatic/ recurrent granulosa cell tumor. See comment. 
Comment: The cytologic appearance of this tumor, along with the overall immuno-phenotype demonstrated by calretinin and inhibin positivity, supports the diagnosis of granulosa cell tumor. Additional studies performed at PhenoPath Laboratory using the more sensitive anti-ER antibody SP1 document expression of estrogen receptor (in contrast to the negative anti-ER studies using the 1D5 clone), further supporting the diagnosis of granulosa cell tumor.

After the diagnosis, patient recalls that she had a procedure for granulosa cell tumor about 30 years ago in Mexico.

Granulosa cell tumor may pose a diagnostic challenge in cytology preparations. First, there is some similarity between the granulosa tumor cells and reactive mesothelial cells. Indistinct cell borders, high nuclear cytoplasmic ratio and indentation of the nuclear membrane are helpful features in distinguishing granulosa tumor cells from mesothelial cells. Secondly, although nuclear features, especially nuclear grooves, are one of the classic features on granulosa cell tumor, they can also be seen in other ovarian tumors such as Brenner tumor and other sex cord-stromal tumor. Other characteristic histological features for granulosa cell tumor, such as Call-Exner bodies, a second population of elongated theca cells, are rarely evident on cytology specimens. Lastly, as occurred in our case, cells of carcinoid, especially pancreatic neuroendocrine tumors in this anatomic site, share many features of granulosa cells. Judicious use of a panel of immunocytochemistry (with the availability of sufficient sampling material) can be of great help in this scenario. Granulosa cell tumor is positive for inhibin, CD99, calretinin, vimentin, CD56, is generally negative for cytokeratin, EMA, BerEp4, and is negative for neuroendocrine markers synaptophysin and chromogranin. Brenner tumor and other sex cord-stromal tumor usually are positive for cytokeratin and EMA.

As illustrated in this case, clinical-pathologic correlation is essential with octreotide scan preventing a diagnostic pitfall of neuroendocrine neoplasia. The on-site cytology interpretation performed for each of 9 EUS-FNA passes played a pivotal role in obtaining adequate viable diagnostic material, considering the sampling difficulty due to extensive tumor necrosis despite the apparent large size of the tumor by imaging study. A more complete ICC panel was thus able to be performed. The ICC results together with cytomorphology led to a diagnosis consistent with the subsequently retrieved clinical history.

Thus, our final note: the full value of FNA is only achieved with the integrated approach: the integration of clinical information, light microscopic analysis, results of ancillary studies, and even the gross appearance of the aspiration material will inform and lead us to a more accurate pathology diagnosis that can help tremendously in directing patient care.

\section{Acknowledgements}

The authors want to express their sincere gratitude to Drs. Nancy B. Kiviat (University of Washington, Seattle, WA), Melissa P. Upton (University of Washington, Seattle, WA) and Stephen J. Rulyak (Evergreen Medical Center, Gastroenterology, Seattle, WA), for their professional guidance, insightful discussions and tremendous technical support. 


\section{Author details}

Lee-Ching Zhu ${ }^{1^{*}}$, Qinghua Feng ${ }^{2}$ and Verena S. Grieco ${ }^{3}$

*Address all correspondence to: zhu.c@ghc.org

1 Anatomic Pathology, Group Health Permanente, Seattle, WA, USA

2 Department of Pathology, School of Medicine, University of Washington, Seattle, WA, USA

3 Harborview Medical Center, Anatomic Pathology, Seattle, WA, USA

\section{References}

[1] Rosch T, Lightdale CJ, Botet JF, et al:Localization of pancreatic endocrine tumors by endoscopic ultrasonography. N Engl J Med.1992;326(26):1721-26.

[2] Voss M, Hammel P, Molas G, et al:Value of endoscopic ultrasound guided fine needle aspiration biopsy in the diagnosis of solid pancreatic masses. Gut.Feb 2000;46(2): 244-9.

[3] Yoshinaga S, Suzuki H, Oda I, Saito Y:Role of endoscopic ultrasound-guided fine needle aspiration (EUS-FNA) for diagnosis of solid pancreatic masses.Dig Endosc; 2011 May;23Suppl 1:29-33.

[4] Zhang S, Defrias DV, Alasadi R, Nayar R:Endoscopic ultrasound-guided fine needle aspiration (EUS-FNA): experience of an academic centre in the USA. Cytopathology; 2010 Feb;21(1):35-43.

[5] Hwang CY, Lee SS, Song TJ, Moon SH, Lee D, Park do H, Seo DW, Lee SK, Kim $\mathrm{MH}$ :Endoscopic ultrasound guided fine needle aspiration biopsy in diagnosis of pancreatic and peripancreatic lesions: a single center experience in Korea. Gut Liver; 2009 Jun;3(2):116-21.

[6] Raddaoui E:Clinical utility and diagnostic accuracy of endoscopic ultrasound-guided fine needle aspiration of pancreatic lesions: Saudi Arabian experience.ActaCytol; 2011;55(1):26-9.

[7] Fisher L, Segarajasingam DS, Stewart C, Deboer WB, Yusoff IF:Endoscopic ultrasound guided fine needle aspiration of solid pancreatic lesions: Performance and outcomes.J GastroenterolHepatol; 2009 Jan;24(1):90-6.

[8] Nakahara O, Yamao K, Bhatia V, Sawaki A, Mizuno N, Takagi T, Shimizu Y, Koshikawa T, Yatabe Y, Baba H:Usefulness of endoscopic ultrasound-guided fine needle 
aspiration (EUS-FNA) for undiagnosed intra-abdominal lymphadenopathy.J Gastroenterol; 2009;44(6):562-7.

[9] Moehler M, Voigt J, Kastor M, Heil M, Sengespeick C, Biesterfeld S, Dippold W, Kanzler S, Galle PR:Endoscopic ultrasonography-guided fine-needle aspiration (EUSFNA) as primary diagnostic tool for unclear lesions in the upper gastrointestinal tract.Dtsch Med Wochenschr; 2011 Feb;136(7):303-8.

[10] Fritscher-Ravens A, Izbicki JR, Sriram PV, et al:Endosonography-guided, fine-needle aspiration cytology extending the indication for organ-preserving pancreatic surgery.Am J Gastroenterol. Sep 2000;95(9):2255-2260.

[11] Erickson, RA: EUS-guided FNA.GastrointestEndosc. 2004 Aug;60(2):267-79.

[12] De Bellis $M$, Sherman S, et al:Tissue sampling at ERCP in suspected malignant biliary strictures, part 1, GastrointestEndosc2002;56:552-61.

[13] De Bellis $M$, Sherman S, et al:Tissue sampling at ERCP in suspected malignant biliary strictures, part 2, GastrointestEndosc2002;56:720-30.

[14] Vandervoort J, Soetikno RM, et al:Accuracy and complication rate of brush cytology from bile duct versus pancreatic duct.GastrointestEndosc 1999;49:322-7.

[15] Rösch T, Lorenz R, Braig C et al: Endoscopic ultrasound in small pancreatic tumors. Z Gastroenterol 1991;29:110-5.

[16] Vilmann P, Saftoiu A:Endoscopic ultrasound-guided fine needle aspiration biopsy:equipment and technique.J GastroenterolHepatol.Nov2006;21(11):1646-1655.

[17] AabakkenL, Silvestri GA, Hawes R, et al:Cost-efficacy of endoscopic ultrasonography with fine-needle aspiration vs. mediastinotomy in patients with lung cancer and suspected mediastinaladenopathy.Endoscopy 1999;31:707-11.

[18] Harewood GC, Wiersema MJ, Edell ES, et al: Cost-minimization analysis of alternative diagnostic approaches in a modeled patient with non-small cell lung cancer and subcarinal lymphadenopathy.Mayo ClinProc 2002;77:155-64.

[19] Harewood GC, Wiersema MJ:A cost analysis of endoscopic ultrasound in the evaluation of esophageal cancer.Am J Gastroenterol 2002;97:452-8.

[20] Harewood GC, Wiersema MJ:A cost analysis of endoscopic ultrasound in the evaluation of pancreatic head adenocarcinoma.Am J Gastroeneerol 2001;96:2651-6.

[21] Chen VK, Arguedas MR, Kilgore ML, et al:A cost-minimization of analysis of alternative strategies in diagnosing pancreatic cancer.Am J Gastroenterol 2004;99:2223-34.

[22] O'Toole D, Palazzo L, Arotcarena R et al:Assessment of complications of EUS-guided fine-needle aspiration.GastrointestEndosc 2001;53:470-4.

[23] Chieng DC, JhalaD, Jhala $\mathrm{N}$ et al:Endoscopic ultrasound -guided fine-needle aspiration biopsy: a study of 103 cases. Cancer 2002;96:232-9. 
[24] Dumonceau JM, Polkowski M, Larghi A, Vilmann P, Giovannini M, Frossard JL, Heresbach D, Pujol B, Fernández-EsparrachG, Vazquez-Sequeiros E, Ginès A:European Society of Gastrointestinal Endoscopy.Indications, results, and clinical impact of endoscopic ultrasound (EUS)-guided sampling in gastroenterology: European Society of Gastrointestinal Endoscopy (ESGE) Clinical Guideline.Endoscopy; 2011 Oct; 43(10):897-912.

[25] Exocrine pancreas.In: Greene FL, Page DL, Fleming ID, et al. editors. AJCC cancer staging handbook. $6^{\text {th }}$ ed. New York: Springer-Verlag;2002. p.182.

[26] Klapman JB, Chang KJ:Endoscopic ultrasound-guided fine-needle injection. GastrointestEndoscClin N Am. 2005 Jan;15(1):169-77.

[27] Tarantino I, Barresi, L:Interventional endoscopic ultrasound: Therapeutic capability and potential.World GastrointestEndosc 2009 Oct 15;1(1):39-44.

[28] Cho CM, Dewitt J, Ai-Haddad M:Echo-endoscopy: new therapeutic frontiers. Minerva GastroenterolDietol. 2011 Jun;57(2):139-58.

[29] Savides TJ, Donohue M, Hunt G, et al:EUS-guided FNA diagnostic yield of malignancy in solid pancreatic masses:a benchmark for quality performance measurement.GastrointestEndosc 2007;66:277-82.

[30] Layfield LJ, Bentz JS, and Gopez EV:Immediate on-site interpretation of fine-needle aspiration smears: a cost and compensation analysis.Cancer 2001;93319-322.

[31] Schwartz MR: Endoscopic ultrasound-guided fine-needel aspiration-time, diagnostic challenges and clnical impact. Cancer Cytopathology 2004;102(4):203-205.

[32] Klapman JB, Logrono R, Dye CE, et al:Clinical impact of on-site cytopathology interpretation on endoscopic ultrasound-guided fine needle aspiration.Am J Gastroenterol 2003;98:1289-94.

[33] Alsohaibani F, Girgis S, SandhaGS:Does onsite cytotechnology evaluation improve the accuracy of endoscopic ultrasound-guided fine-needle aspiration biopsy?Can J Gastroenterol. 2009 Jan;23(1):26-30.

[34] Jhala N, Jhala D,Etoum I, Vickers SM, et a:Endoscopic ultrasound-guided fine-needle aspiration biopsy: a powerful tool to obtain samples from small lesions.Cancer 2004;102(4):239-246.

[35] Erickson RA, Sayage-Rable L, Beissner S:Factors predicting the number of EUS-guided fine-needle passes for diagnosis of pancreatic malignancies. Gastrointestinal Endoscopy 2000;51(2):184-190.

[36] Jhala NC, Jhala DN, Chhieng DC, et a:Endoscopic ultrasound-guided fine-needle aspiration-a cytopathologist's perspective.AJCP 2003; 120(3):351-367. 
[37] JhalaNC,Eltoum IA, Eloubeidi MA, et al:Providing on-site diagnosis of malignancy on endoscopic-ultrasound-guided fine-needle aspiration: should it be done?Annals DiagPathol 2007;11:176-181.

[38] Dumonceau JM, Koessler T, vanHooft JE, Fockens P:Endoscopic ultrasonographyguided fine needle aspiration: Relatively low sensitivity in the endosonographer population.World J Gastroenterol; 2012 May 21;18(19):2357-63.

[39] Iqbal S, Friedel D, Gupta M, Ogden L, Stavropoulos SN:Endoscopic-ultrasoundguided fine-needle aspiration and the role of the cytopathologist in solid pancreatic lesion diagnosis.Patholog Res Int; 2012;2012:317167.

[40] Cherian PT, Mohan P, Douiri A, Taniere P, Hejmadi RK, Mahon BS:Role of endoscopic ultrasound-guided fine-needle aspiration in the diagnosis of solid pancreatic and peripancreatic lesions: is onsite cytopathology necessary?HPB (Oxford); 2010 Aug;12(6):389-95.

[41] HikichiT, Irisawa A, Bhutani MS, et al:Endoscopic ultrasound-guided fine-needle aspiration of solid pancreatic masses with rapid on-site cytological evaluation by endosonographers without attendance of cytopathologists.J Gastroenterol2009;44(4):322-8.

[42] Nguyen YP, Maple, JT, Zhang, Q, et al:Reliability of gross visual assessment of specimen adequacy during EUS-guided FNA of pancreatic masses.GastrointestEndosc 2009;69(7):1264-70.

[43] Boujaoude J:Role of endoscopic ultrasound in diagnosis and therapy of pancreatic adenocarcinomas. World J Gastro 2007;13(27):3662-3666.

[44] Eltoum IA, Jhala CD, Crowe DR, et al:Cumulative sum procedure in evaluation of EUS-guided FNA cytology: the learning curve and diagnostic performance beyond sensitivity and specificity.Cytopathology 2007;18:143-50.

[45] Nasuti JF, Gupta PK and Baloch ZW:Diagnostic value and cost-effectiveness of onsite evaluation of fine-needle aspiration specimens: review of 5,688 cases.Diagn. Cytopathol. 2002;27:1-4.

[46] Shin HJC, Lahoti S, and Sneige N:Endoscopic ultrasound-guided fine-needle aspiration in 179 cases.Cancer (Cancer Cytopathol) 2002;96:174-80.

[47] Savoy AD, Raimondo M, Woodward TA, et al:Can endosonographers evaluate onsite cytologic adequacy?A comparison with cytotechnologists.GastrointestEndosc 2007;65(7):953-7.

[48] de Jong K, Poley JW, van Hooft JE, Visser M, Bruno MJ, Fockens P:Endoscopic ultrasound-guided fine-needle aspiration of pancreatic cystic lesions provides inadequate material for cytology and laboratory analysis: initial results from a prospective study.Endoscopy; 2011 Jul;43(7):585-90. 
[49] Karim Z, Walker B, Lam E:Lymphoepithelial cysts of the pancreas: the use of endoscopic ultrasound-guided fine-needle aspiration in diagnosis.Can J Gastroenterol; 2010 Jun;24(6):348-50.

[50] Barresi L, Tarantino I, Granata A, Curcio G, Traina M:Pancreatic cystic lesions: How endoscopic ultrasound morphology and endoscopic ultrasound fine needle aspiration help unlock the diagnostic puzzle. World J GastrointestEndosc; 2012 Jun 16;4(6): 247-59.

[51] Bhatia V, Rastogi A, Saluja SS, Kumar M, Bihari C, Kalayarasan R, Gupta NL:Cystic pancreatic lymphangioma. The first report of a preoperative pathological diagnosis by endoscopic ultrasound-guided cyst aspiration. JOP; 2011 Sep;12(5):473-6.

[52] Coe AW, Evans J, Conway J:Pancreas cystic lymphangioma diagnosed with EUSFNA. JOP; 2012 May;13(3):282-4.

[53] ZhuLC and Grieco V:Diagnostic value of unusual gross appearance of aspirated material from endoscopic ultrasound-guided fine needle aspiration of pancreatic and peripancreatic cystic lesions.ActaCytol. 2008 Sep-Oct;52(5):535-40.

[54] Dev V, Shah D, Gaw F, Lefor AT:Gastric outlet obstruction secondary to post cholecystectomy biloma:case report and review of the literature. JSLS. 1998;2(2):185-8.

[55] Chang ML, Lin DY:Symptomless cyst formation at the location of a biloma resolved with a single aspiration:case report. Chang Gung Med J. 2000;23(12):794-8.

[56] Ponnudurai, R:Endoscopic ultrasound-guided drainage of a biloma: A novel approach. Endoscopy 2006;38:199.

[57] Policarpio-Nicolas,ML, Shami VM, Kahaleh M, Adams RB, Mallery S, Stanley MW, Bardales RH, Stelow EB:Fine-needle aspiration cytology of pancreatic lymphoepithelial cysts. Cancer (Cancer Cytopathol) 2006;108:501-6.

[58] Fujiwara H, Kohno N, Nakaya S, Ishikawa Y:Lymphoepithelial cyst of the pancreas with sebaceous differentiation. J Gastroenterol 2000;35:396-401.

[59] Adsay NV:Cystic lesions of the pancreas.Modern Pathology, 2007;20:S71-S93.

[60] Solcia EN, Capella C, Kloppel G:Tumors of the pancreas. Fascicle 20 in Atlas of Tumor Pathology, $3^{\text {rd }}$ series. Armed Forces Institute of Pathology, Washington DC:1997, 215-223.

[61] Weinstein LJ: Pancreas, in Cytology, Diagnostic principles and clinical correlates. Cibas ES and Ducatman BS, Saunders, Philadelphia 2003, 367-382.

[62] Zhu L and GriecoV:Identifying mucin on cytology specimens from EUS-FNA procedures.Digestive Disease Week, Washington, DC, 2007.

[63] Ringel J, Löhr M:The MUC gene family: their role in diagnosis and early detection of pancreatic cancer.Mol Cancer. 2003 Jan 7;2:9 
[64] Hruban RH, Maitra A, Kern SE, Goggins M:Precursors to pancreatic cancer.GastroenterolClin North Am. 2007 Dec;36(4):831-49.

[65] Albores-Saavedra J, Simpson K, Dancer YJ, Hruban :.Intestinal type adenocarcinoma: a previously unrecognized histologic variant of ductal carcinoma of the pancreas.Ann DiagnPathol. 2007 Feb;11(1):3-9.

[66] Furukawa T, Klöppel G, VolkanAdsay N, et al:Classification of types of intraductal papillary-mucinous neoplasm of the pancreas: a consensus study.Virchows Arch. 2005 Nov;447(5):794-9. Epub2005 Aug 9.

[67] Giorgadze TA, Peterman H, Baloch ZW, Furth EE, Pasha T, Shiina N, Zhang PJ, Gupta PK:Diagnostic utility of mucin profile in fine-needle aspiration specimens of the pancreas: an immunohistochemical study with surgical pathology correlation.2006 Jun 25;108(3):186-97.

[68] Zhu L and Peck A: Endoscopic ultrasound guided fine needle aspiration of pancreatic endocrine neoplasms:Diagnostic challenges and the role of immunocytochemistry.Check Sample, ASCP, 2008.

[69] Eloubeidi MA, Tamhane AR, Buxbaum J:Unusual, metastatic, or neuroendocrine tumor of the pancreas:a diagnosis with endoscopic ultrasound-guided fine-needle aspiration and immunohistochemistry.Saudi J Gastroenterol;2012 Mar-Apr;18(2):99-105.

[70] Chang F, Vu C, Chandra A, Meenan J, Herbert A:Endoscopic ultrasound-guided fine needle aspiration cytology of pancreatic neuroendocrine tumours: cytomorphological and immunocytochemical evaluation. Cytopathology. Feb 2006;17(1):10-17.

[71] NotoharaK,Hamazaki S, Tsukayama C, et al:Solid-pseudopapillary tumor of the pancreas: immunohistochemical localization of neuroendocrine markers and CD10. Am J SurgPathol. Oct 2000;24(10):1361-1371.

[72] Portela-Gomes GM, Hacker GW, Weitgasser R:Neuroendocrine cell markers for pancreatic islets and tumors.ApplImmunohistochemMolMorphol. 2004 Sep;12(3):183-92.

[73] Carlsson J:Potential for clinical radionuclide-based imaging and therapy of common cancers expressing EGFR-family receptors.Tumour Biol. 2012 Jun;33(3):653-9. Epub 2012 Jan 7.

[74] Matthaios D, Zarogoulidis P, Balgouranidou I, Chatzaki E, Kakolyris S:Molecular pathogenesis of pancreatic cancer and clinical perspectives.Oncology. 2011;81(3-4): 259-72. Epub 2011 Nov 23.

[75] Stella GM, Luisetti M, Inghilleri S, CemmiF,Scabini R, Zorzetto M, Pozzi E:Targeting EGFR in non-small-cell lung cancer: lessons, experiences, strategies.Respir Med. 2012 Feb;106(2):173-83. Epub 2011 Nov 21

[76] Bohanes P, LaBonte MJ, Winder T, Lenz HJ:Predictive molecular classifiers in colorectal cancer.SeminOncol. 2011 Aug;38(4):576-87. 
[77] Cervera P, Fléjou JF:Changing pathology with changing drugs: tumors of the gastrointestinal tract.Pathobiology.2011;78(2):76-89. doi: 10.1159/000315535. Epub 2011 Jun 15.

[78] Saijo N:Critical comments for roles of biomarkers in the diagnosis and treatment of cancer.Cancer Treat Rev. 2012 Feb;38(1):63-7. Epub 2011 Jun 8.

[79] William WN Jr:Oral premalignant lesions: any progress with systemic therapies?CurrOpinOncol. 2012 May;24(3):205-10.

[80] Smith RA, Tang J, Tudur-Smith C, Neoptolemos JP, Ghaneh P:Meta-analysis of immunohistochemical prognostic markers in resected pancreatic cancer.Br J Cancer. 2011 Apr 26;104(9):1440-51. Epub 2011 Mar 29. Review.

[81] Larsen AK, Ouaret D, El Ouadrani K, Petitprez A:Targeting EGFR and VEGF(R) pathway cross-talk in tumor survival and angiogenesis.PharmacolTher. 2011 Jul; 131(1):80-90. Epub 2011 Mar 23.

[82] Murphy M, Stordal B:Erlotinib or gefitinib for the treatment of relapsed platinum pretreated non-small cell lung cancer and ovarian cancer: a systematic review.Drug Resist Updat. 2011 Jun;14(3):177-90. Epub 2011 Mar 24.

[83] Iacopetta B, Grieu F, Amanuel B:Microsatellite instability in colorectalcancer.Asia Pac J ClinOncol. 2010 Dec;6(4):260-9. doi: 10.1111/j.1743-7563.2010.01335.x. Epub 2010 Oct 26.

[84] Imai K, Yamamoto H:Carcinogenesis and microsatellite instability: the interrelationship between genetics and epigenetics.Carcinogenesis. 2008 Apr;29(4):673-80. Epub 2007 Oct 17.

[85] Lawes DA, SenGupta S, BoulosPB:The clinical importance and prognostic implications of microsatellite instability in sporadic cancer.Eur J SurgOncol. 2003 Apr;29(3): 201-12.

[86] Chapusot C, Martin L, Puig PL, Ponnelle T, Cheynel N, Bouvier AM, Rageot D, Roignot P, Rat P, Faivre J, Piard F:What is the best way to assess microsatellite instability status in colorectal cancer? Study on a population base of 462 colorectalcancers.Am J SurgPathol. 2004 Dec;28(12):1553-9.

[87] Shia J, Ellis NA, Paty PB, Nash GM, Qin J, Offit K, Zhang XM, Markowitz AJ, Nafa K, Guillem JG, Wong WD, Gerald WL, KlimstraDS:Value of histopathology in predicting microsatellite instability in hereditarynonpolyposiscolorectal cancer and sporadic colorectalcancer.Am J SurgPathol. 2003 Nov;27(11):1407-17.

[88] Edmonston TB, Cuesta KH, Burkholder S, Barusevicius A, Rose D, Kovatich AJ, Boman B, Fry R, Fishel R, Palazzo JP:Colorectal carcinomas with high microsatellite instability: defining a distinct immunologic and molecular entity with respect to prognosticmarkers.Hum Pathol. 2000 Dec;31(12):1506-14. 
[89] Kouniavsky G, Zeiger MA:The quest for diagnostic molecular markers for thyroid nodules with indeterminate or suspicious cytology.J SurgOncol. 2012 Apr 1;105(5): $438-43$

[90] Bartolazzi A, Bellotti C, Sciacchitano S:Methodology and technical requirements of the galectin-3 test for the preoperative characterization of thyroidnodules.ApplImmunohistochemMolMorphol. 2012 Jan;20(1):2-7. Review.

[91] Freitas BC, Cerutti J:.Genetic markers differentiating follicular thyroid carcinoma from benign lesions.Mol Cell Endocrinol. 2010 May 28;321(1):77-85. Epub 2009 Nov 20.

[92] Nikiforova MN, NikiforovYE:Molecular diagnostics and predictors in thyroid cancer.Thyroid. 2009 Dec;19(12):1351-61.

[93] Arora N, Scognamiglio T, Zhu B, Fahey TJ $3^{\text {rd }}$ :Do benign thyroid nodules have malignant potential? An evidence-based review.World J Surg. 2008 Jul;32(7):1237-46.

[94] Carpi A, Nicolini A, Marchetti C, Iervasi G, Antonelli A, Carpi F:Percutaneous largeneedle aspiration biopsy histology of palpable thyroid nodules: technical and diagnostic performance.Histopathology. 2007 Aug;51(2):249-57.

[95] Kapur U, WojcikEM:Follicular neoplasm of the thyroid--vanishing cytologicdiagnosis?DiagnCytopathol. 2007 Aug;35(8):525-8.

[96] Ogilvie JB, Piatigorsky EJ, Clark OH:Current status of fine needle aspiration for thyroidnodules.Adv Surg. 2006;40:223-38.

[97] Carpi A, Mechanick JI, Nicolini A, Rubello D, Iervasi G, Bonazzi V, Giardino :Thyroid nodule evaluation: what have we really learned from recent clinical guidelines? BiomedPharmacother. 2006 Sep;60(8):393-5. Epub 2006 Aug 4.

[98] Mechanick JI, Carpi A:Progress in the preoperative diagnosis of thyroid nodules: managing uncertainties and the ultimate role for molecularinvestigation.BiomedPharmacother. 2006 Sep;60(8):396-404. Epub 2006 Aug 1

[99] Lambros MB, Natrajan R, Reis-FilhoJS:Chromogenic and fluorescent in situ hybridization in breast cancer.HumPathol. 2007 Aug;38(8):1105-22.

[100] Lee JA, Shaheen M, Walke T, Daly M:Clinical and health economic outcomes of alternative HER2 test strategies for guiding adjuvant trastuzumabtherapy.Expert Rev Pharmacoecon Outcomes Res. 2011 Jun;11(3):325-41.

[101] Ross JS:Update on HER2 testing for breast and upper gastrointestinal tract cancers.Biomark Med. 2011 Jun;5(3):307-18.

[102] Penault-Llorca F, Bilous M, Dowsett M, Hanna W, OsamuraRY, Rüschoff J, van de Vijver M:Emerging technologies for assessing HER2amplification.Am J ClinPathol. 2009 Oct;132(4):539-48. 
[103] Ross JS:Breast cancer biomarkers and HER2 testing after 10 years of anti-HER2therapy.Drug News Perspect. 2009 Mar;22(2):93-106.

[104] Sauter G, Lee J, Bartlett JM, Slamon DJ, Press MF:Guidelines for human epidermal growth factor receptor 2 testing: biologic and methodologicconsiderations.JClinOncol. 2009 Mar 10;27(8):1323-33. Epub 2009 Feb 9.

[105] Cuadros M, Villegas R:Systematicreview of HER2breast cancer testing.ApplImmunohistochemMolMorphol. 2009 Jan;17(1):1-7.

[106] Bayani J, Squire JA:Fluorescence in situ Hybridization (FISH).CurrProtocCell Biol. 2004 Sep;Chapter 22:Unit 22.4.

[107] Shabaik A, Lin G, Peterson M, HastehF, Tipps A, Datnow B, Weidner N:Reliability of Her2/neu, estrogen receptor, and progesterone receptor testing by immunohistochemistry on cell block of FNA and serous effusions from patients with primary and metastatic breast carcinoma.DiagnCytopathol. 2011 May;39(5):328-32.

[108] Hanley KZ, Birdsong GG, Cohen C, SiddiquiMT:Immunohistochemical detection of estrogen receptor, progesterone receptor, and human epidermal growth factor receptor 2 expression in breast carcinomas: comparison on cell block, needle-core, and tissue block preparations.Cancer. 2009 Aug 25;117(4):279-88.

[109] Barroca H, Carvalho JL, da Costa MJ,Cirnes L, Seruca R, Schmitt FC:Detection of Nmyc amplification in neuroblastomas using Southern blotting on fine needle aspirates.ActaCytol. 2001 Mar-Apr;45(2):169-72.

[110] Fröstad B, Martinsson T, Tani E, Falkmer U, Darnfors C, Skoog L, Kogner P:The use of fine-needle aspiration cytology in the molecular characterization of neuroblastoma in children.Cancer. 1999 Apr 25;87(2):60-8.

[111] Constantinou M, Binka-Kowalska A, Borkowska E, Zajac E, Jałmuzna P, Matych J, Nawrocka A, Kałuzewski B:Application of multiplexFISH, CGH and MSSCP techniques for cytogenetic and molecular analysis of transitional cell carcinoma (TCC) cells in voided urine specimens.J Appl Genet. 2006;47(3):273-5.

[112] Halling KC, KippBR:Bladder cancer detection using FISH (UroVysion assay).AdvAnatPathol. 2008 Sep;15(5):279-86.

[113] vanRhijn BW, van der Poel HG, van der KwastTH:Urine markers for bladder cancer surveillance: a systematic review.Eur Urol. 2005 Jun;47(6):736-48. Epub 2005 Mar 23.

[114] Dey P:Urinary markers of bladder carcinoma.ClinChimActa. 2004 Feb;340(1-2):57-65.

[115] Feng Q, Balasubramanian, A, Hawes SE et al:Detection of hypermethylated genes in women with and without cervical neoplasia.J Natl Cancer Inst 2005;97:273-82.

[116] Hawes SE, Stern JE, Feng Q, Wiens LW, Rasey JS, Lu H, Kiviat NB, Vesselle H:DNAhypermethylation of tumors from non-small cell lung cancer (NSCLC) patients is as- 
sociated with gender and histologic type.Lung Cancer. 2010 Aug;69(2):172-9. Epub 2009 Nov 28.

[117] Feng Q, Deftereos G, Hawes SE, Stern JE, Willner JB, Swisher EM, Xi L, Drescher C, Urban N, Kiviat NB:DNA hypermethylation, Her-2/neu overexpression and p53 mutations in ovarian carcinoma.GynecolOncol.2008 Nov;111(2):320-9. Epub 2008 Aug 30.

[118] Feng Q, Hawes SE, Stern JE, Dem A, Sow PS, Dembele B, Toure P, Sova P, Laird PW, Kiviat NB:Promoter hypermethylation of tumor suppressor genes in urine from patients with cervical neoplasia.CancerEpidemiol Biomarkers Prev. 2007 Jun;16(6):1178-84. 